\title{
Probing the relative contribution of the first and second responses to sensory gating indices: A meta-analysis
}

\author{
WEN-PIN CHANG, ${ }^{a}$ CYNTHIA L. ARFKEN, ${ }^{\mathrm{b}}$ MONICA P. SANGAL ${ }^{\mathrm{c}}$ AND \\ NASH N. BOUTROS ${ }^{b}$ \\ ${ }^{a}$ Department of Occupational Therapy, Creighton University, Omaha, Nebraska, USA \\ ${ }^{\mathrm{b}}$ Department of Psychiatry and Neurosciences, Wayne State University School of Medicine, Detroit, Michigan, USA \\ ${ }^{\mathrm{c}}$ Department of Biological Chemistry, University of Michigan, Ann Arbor, Michigan, USA
}

\begin{abstract}
Sensory gating deficit in schizophrenia patients has been well-documented. However, a central conceptual issue, regarding whether the gating deficit results from an abnormal initial response (S1) or difficulty in attenuating the response to the repeating stimulus (S2), raise doubts about the validity and utility of the S2/S1 ratio as a measure of sensory gating. This meta-analysis study, therefore, sought to determine the consistency and relative magnitude of the effect of the two essential components (S1 and S2) and the ratio. The results of weighted random effects meta-analysis revealed that the overall effect sizes for the S1 amplitude, S2 amplitude, and P50 S2/S1 ratio were - 0.19 (small), 0.65 (medium to large), and 0.93 (large), respectively. These results confirm that the S2/S1 ratio and the repeating (S2) stimulus differ robustly between schizophrenia patients and healthy controls in contrast to the consistent but smaller effect size for the S1 amplitude. These findings are more likely to reflect defective inhibition of repeating redundant input rather than an abnormal response to novel stimuli.
\end{abstract}

Descriptors: Sensory gating, Schizophrenia, P50, Gating out

Deficits in both the early pre-attentive stage and later evaluative processes of information processing are well-documented in schizophrenia patients (e.g., Turetsky, Bilker, Siegel, Kohler, \& Gur, 2009). The putative mechanism underlying these deficits is the inability to inhibit irrelevant or redundant information inflow (Venables, 1964). This inhibitory control, or gating of neuronal responses to afferent information, is believed to be essential for sustaining attention in a changing environment and for appropriate responses to afferent stimuli (Hubel \& Wiesel, 1959). It has been argued that the sensory gating problem may result from neuronal hyper-excitability due to a flaw in neuronal inhibitory pathways of cortical and sub-cortical areas (Adler et al., 1982; Flach et al., 1996; Freedman, Waldo, Bickford-Wimer, \& Nagamoto, 1991).

To study this sensory gating mechanism, an auditory P50 conditioning (S1)-testing (S2) paradigm is often used while recording the electroencephalogram (EEG) (Adler et al., 1982; Freedman et al., 1987, 1991). In this paired stimulus paradigm (PSP), two identical auditory stimuli are presented as pairs (500 ms apart between clicks or sounds) with an inter-trial interval (ITI) of 8 to $10 \mathrm{~s}$ between the pairs (e.g., Freedman et al., 1987; Zouridakis \& Boutros, 1992). The P50 mid-latency auditory evoked response (MLAER) attained from the PSP is the most positive peak approximately $40-90 \mathrm{~ms}$ after the onset of auditory

Address correspondence to: Wen-Pin Chang, Department of Occupational Therapy, Creighton University, 2500 California Plaza, Omaha, NE 68178. E-mail: wenpinchang@creighton.edu stimuli (e.g., Boutros, Korzyukov, Jansen, Feingold, \& Bell, 2004). The degree of sensory gating, denoted as $\mathrm{T} / \mathrm{C}$ ratio or $\mathrm{S} 2 /$ $\mathrm{S} 1$ ratio, is determined by the ratio of the amplitude of the P50 response to the testing click (T or S2) to the amplitude of the P50 response to the conditioning click (C or S1; e.g., Freedman et al., 1987). In healthy individuals, the $S 2$ amplitude is usually diminished by over $60 \%$ of the S1 amplitude (Moxon, Gerhardt, Gulinello, \& Adler, 2003). In schizophrenia patients, however, the amount or percent of the S2 amplitude decrement over the S1 amplitude has not been clearly documented.

Despite the publication of three meta-analyses supporting the presence of P50 sensory gating deficit in schizophrenia patients (Bramon, Rabe-Hesketh, Sham, Murray, \& Frangou, 2004; de Wilde, Bour, Dingemans, Koelman, \& Linszen, 2007a; Patterson et al., 2008), there are methodological and conceptual concerns regarding the use of the $\mathrm{T} / \mathrm{C}$ or $\mathrm{S} 2 / \mathrm{S} 1$ ratio. These concerns include the low noise to signal ratio (SNR), the low test-retest reliability in healthy controls (Fuerst, Gallinat, \& Boutros, 2007; Rentzsch, Jockers-Scherübl, Boutros, \& Gallinat, 2008; Smith, Boutros, \& Schwarzkopf, 1994), and the lack of blinding during data collection in some studies (Boutros, 2008). Other methodological concerns, such as use of antipsychotic medication and illness duration, were not found to be important in the three prior meta-analyses (Bramon et al., 2004; de Wilde et al., 2007a; Patterson et al., 2008). Both de Wilde et al. (2007a) and Patterson et al. (2008) proposed specific recommendations for future sensory gating research to address methodological issues (see de Wilde et al., 2007a; Patterson et al., 2008 for details). However, none of 
these meta-analyses have addressed conceptual issues of sensory gating.

The central conceptual factor is the relative magnitude of both the responses to S1 and S2 stimuli to the noted decreased decrement of the response to $\mathrm{S} 2$ stimuli in schizophrenia patients as compared to the decrement of S2 responses recorded from healthy control subjects. This decrement is most commonly assessed by dividing the amplitude of the responses to $\mathrm{S} 2$ by the amplitudes of the responses to $\mathrm{S} 1$. Although the $\mathrm{S} 2 / \mathrm{S} 1$ ratio is most widely used to assess gating, the S1-S2 mathematical difference has also been used (Smith et al., 1994). The more widely employed ratio is taken as an operational measure of the brain's habituation or gating capacity. An elevated ratio is taken to denote decreased brain ability to habituate or suppress irrelevant or redundant incoming sensory input (Freedman et al., 1987). An elevated ratio can result from an abnormally low response to S1 stimuli, or a decreased attenuation of the $\mathrm{S} 2$ response. The physiological implications of the two scenarios are different and significantly impact the understanding of the physiological deviations (Boutros et al., 2009). We have previously proposed that two physiological aberrations, abnormally low S1 responses and abnormally decreased ability to suppress $\mathrm{S} 2$ responses, are demonstrated in schizophrenia patients and that these two abnormalities may or may not be completely independent (Boutros et al., 2009). We propose that, on a fundamental level, if there is no gating abnormality, the ratio should remain low no matter how small the response to $\mathrm{S} 1$ is, unless there is a yet unidentified floor effect. Similarly, if a gating deficit exists, the amplitude decrement from $\mathrm{S} 1$ to $\mathrm{S} 2$ should remain small no matter how large the response to $\mathrm{S} 1$ is.

Stemming from earlier work (Jansen, Hegde, \& Boutros, 2004) and more recent work (Turetsky et al., 2009), this issue is critical to the P50 gating literature. For instance, both Blumenfeld and Clementz (2001) and Jansen et al. (2004) asserted that a decreased $\mathrm{S} 1$ amplitude in schizophrenia patients is the major determinant of the elevated P50 S2/S1 ratio noted in these individuals. Moreover, Johannesen et al. (2005) noticed an abnormally small $\mathrm{S} 1$ response in the presence of a normal $\mathrm{S} 2$ response leading to a high P50 S2/S1 ratio among schizophrenia patients, and their findings are further supported by a recent study (i.e., Brenner et al., 2009).

Studies questioning the relative importance of the S1 amplitudes, however, indicate that poor sensory gating, i.e., high P50 $\mathrm{S} 2 / \mathrm{S} 1$ ratio, is not associated with the $\mathrm{S} 1$ amplitude (Clementz, Geyer, \& Braff, 1997; Jin et al., 1997). Also, Freedman et al. (1987) indicated that poor sensory gating is a result of a lack of gating out the redundant S2 stimuli. Thus, a significant disagreement exists regarding whether the P50 S2/S1 ratio is the result of a defective response to $\mathrm{S} 1$ stimuli or a hitherto unidentified interaction between the $\mathrm{S} 1$ and $\mathrm{S} 2$ responses in both schizophrenia patients and healthy subjects (e.g., Blumenfeld \& Clementz, 2001; Boutros \& Belger, 1999; Clementz et al., 1997; Jin et al., 1997; Johannesen et al., 2005).

It is thus fundamental for future sensory gating research utilizing the PSP to establish whether the paradigm examines the habituation process (i.e., the degree of decrement from S1 to S2) or that the decrement noted is simply a reflection of the abnormal response to $\mathrm{S} 1$ stimuli. A consistently stronger association of $\mathrm{S} 1$ values compared to that of $\mathrm{S} 2$ and the $\mathrm{S} 2 / \mathrm{S} 1$ ratios would support the latter possibility and throw serious doubt regarding the implications of the PSP abnormalities reported in association with schizophrenia. Therefore, the purpose of this meta-analysis is to ascertain the relative magnitude of the $\mathrm{S} 1, \mathrm{~S} 2$, and $\mathrm{S} 2 / \mathrm{S} 1$ effect sizes.

\section{Method \\ Literature Search}

The literature search began with three published meta-analyses of sensory gating in schizophrenia patients and healthy controls (i.e., Bramon et al., 2004; de Wilde et al., 2007a; Patterson et al., 2008). The Bramon et al. (2004) study searched sensory gating papers published between January 1994 and August 2003 in the databases MEDLINE and SCIENCE CITATION INDEX using the keywords: P50 AND [Psychosis OR Schizophrenia]. They also carried out a search for papers published between January and August 2003 in several journals and included 20 studies in their analysis. The de Wilde et al. (2007a) study used the keywords P50 and schizophrenia to conduct a search for papers published between 1982 and October 2006 in the databases MEDLINE, PUBMED, and Science Direct, and crossed-referenced citations. They included 34 studies in their analysis. The Patterson et al. (2008) study reviewed studies published between 1982 and 2006 as found in PUBMED. They included 39 studies in their analyses. Across these three metaanalyses, 52 studies were included.

For our meta-analysis, we started with these 52 studies and added 18 studies published between January 2007 and December 2009 found in the databases MEDLINE, PUBMED, and Science Direct using the keywords P50 sensory gating and schizophrenia. Thus, there was the potential for 70 studies to be analyzed before subsequent review for inclusion.

\section{Inclusion Criteria}

As some studies did not include sufficient information for analysis, we established a priori the following inclusion criteria: (1) report separately the number of participants in each of the schizophrenia and healthy control groups, (2) report separately the mean and standard deviation $(S D)$ of the S1 and S2 P50 amplitudes in each of the schizophrenia and healthy control groups, and (3) report separately the mean and SD of P50 S2/S1 ratio in each of the schizophrenia and healthy control groups. If studies reported P50 amplitudes and ratios in plots or graphed the findings only, they were not included in the analysis.

After carefully reviewing the articles based on these inclusion criteria, 35 articles (publications) were included in this metaanalysis with a total number of 58 different comparisons between schizophrenia patients and healthy controls. The 58 different comparisons were obtained as some of the articles included more than one schizophrenia patient group. Among these 35 articles, four had been included in all three previously published metaanalyses, nine were included in at least two meta-analyses, and four were in only one previously published meta-analysis. Thus, 18 out of the 35 included articles were not included in any of the three previous meta-analyses.

\section{Data Collected}

Prior to analysis, reported standard errors of mean were converted to standard deviations. Reported P50 suppression rates were converted to the $\mathrm{S} 2 / \mathrm{S} 1$ ratio by subtracting the $\mathrm{S} 2$ percent reduction from $100 \%$ and dividing by 100 . Thus, a $35 \%$ reduction in $\mathrm{S} 2$ would convert to a 0.65 ratio. 


\section{Meta-Analysis Procedure and Data Analysis}

Consistent with the three meta-analysis studies of P50 sensory gating in schizophrenia patients (i.e., Bramon et al., 2004; de Wilde et al., 2007a; Patterson et al., 2008), the effect sizes for the means of the S1 amplitude, S2 amplitude, and S2/S1 ratio were calculated using Cohen's $d$, or the difference between the mean of control group and the mean of schizophrenia group divided by the pooled standard deviation. In addition, random effects metaanalysis was used, consistent with two of the previous studies (Bramon et al., 2004; Patterson et al., 2008). The random effects meta-analysis assumes that true effect size has normal distribution from a population of studies investigated and provides an overall mean estimation of effect size and its confidence interval. Although the fixed effect analysis was conducted and used the inverse variance method of weighting, only the results of the random effects models are present. The models were weighted using the DerSimonian-Laird method (DerSimonian \& Laird, 1986).

As suggested by de Wilde et al. (2007a), we calculated the overlap statistic (OL\%) to examine the overlap in the P50 measure distribution between schizophrenia patients and healthy controls. When $d$ is zero, there is $100 \%$ overlap between the two groups. If $d$ is one, it equates to $44.6 \%$ overlap (Zakzanis, 2001). Publication bias was examined by calculating the number of unpublished studies, or Nfs (Orwin, 1983), needed to obtain a small effect size (Cohen, 1988), and by examining funnel plots. Homogeneity was tested using the Q statistic, with the magnitude of homogeneity quantified with $\mathrm{I}^{2}$. Effect size calculations were conducted using MIX Pro 2.0 software (BiostatXL.com) and the OL \% was calculated using Excel software (Microsoft), a spreadsheet designed by DeCoster and Iselin (Stat-Help.com).

\section{Results}

Table 1 presents the means of the reported P50 S2/S1 ratios and amplitudes for both schizophrenia patients and healthy controls from the 35 articles (58 comparisons). For healthy controls, the mean $\mathrm{S} 1$ amplitude ranged from $0.79 \mu \mathrm{V}$ to $5.93 \mu \mathrm{V}$, the mean S2 amplitude ranged from $0.18 \mu \mathrm{V}$ to $2.89 \mu \mathrm{V}$, and the mean P50 S2/ $\mathrm{S} 1$ ratio ranged from 0.16 to 0.94 . Among the schizophrenia patients, the mean $\mathrm{S} 1$ amplitude ranged from $1.40 \mu \mathrm{V}$ to $6.39 \mu \mathrm{V}$, the mean S2 amplitude ranged from $0.80 \mu \mathrm{V}$ to $3.73 \mu \mathrm{V}$, and the mean P50 S2/S1 ratio ranged from 0.32 to 1.42 . Among the 58 comparisons, schizophrenia patients had a smaller mean S1 amplitude than controls in 38 comparisons $(65.52 \%)$. For the S2, schizophrenia patients had a larger mean S2 amplitude than controls in 52 out of 58 comparisons $(89.66 \%)$. For the S2/S1 ratio, schizophrenia patients had a larger mean ratio than healthy controls in 56 comparisons $(96.55 \%)$.

Figure 1a, 1b, and 1c present the forest plots of the effect size for the S1 amplitude, S2 amplitudes, and S2/S1 ratio, respectively. Each square is located at the estimate of the effect size with the size of the square proportional to the sample size. The blue horizontal lines indicate the $95 \%$ confidence interval of the effect size for each comparison. The red line indicates the estimated effect size with its corresponding prediction interval. Table 2 presents the effect sizes of the S1 amplitude, S2 amplitude, and P50 S2/S1 ratio for 58 comparisons between schizophrenia patients and healthy controls. The effect size for the S1 amplitude from the random effects model was -0.19 with the standard error of 0.049 and the $95 \%$ confidence interval of -0.29 to
-0.10 . The OL statistic ranged from $38.78 \%$ to $100 \%$ (mean $=76.83 \% \pm 15.72 \%$ ). For the combined effect size, the OL statistic showed that there was $85.74 \%$ overlap in the mean S1 amplitude between schizophrenia patients and healthy controls. There was an indication of heterogeneity in the S1 amplitude across the studies, Cochrane $\mathrm{Q}=116.69, p<.0005$, $\mathrm{I}^{2}=51.15 \%$. The Orwin's Nfs for publication bias showed that there were no additional studies needed to support the null hypothesis of at least a small effect size $(d=0.2)$ as the combined effect size was small; the funnel plot of the S1 amplitude (see Figure 2) supported the lack of publication bias due to a symmetrical distribution.

For the S2 amplitude, the effect size in each comparison ranged from -0.42 to 4.53 . The effect size for the $\mathrm{S} 2$ amplitude from the random effects model was 0.65 with the standard error of 0.084 and the $95 \%$ confidence interval of 0.48 to 0.81 . The OL statistic ranged from $1.18 \%$ to $100 \%$ (mean $=63.59 \% \pm$ $24.30 \%$ ). For the combined effect size, the OL statistics showed that there was $59.62 \%$ overlap in the mean S2 amplitude between schizophrenia patients and healthy controls. There was also an indication of heterogeneity, Cochrane $\mathrm{Q}=344.61 p<.0005$, $\mathrm{I}^{2}=83.46 \%$. The Orwin's Nfs indicated that 131 studies were necessary to reduce the combined effect size of the S2 amplitude to a small effect size. The funnel plot of the S2 amplitude (see Figure 3) did not suggest a publication bias.

For the P50 S2/S1 ratio, the effect size in each comparison ranged from -0.29 to 3.97 . The effect size from the random effects model was 0.93 with the standard error of 0.088 and a $95 \%$ confidence interval of 0.75 to 1.10 . The OL statistics showed an overlap of $2.42 \%$ to $98.28 \%$ with the mean of $51.44 \% \pm 23.63 \%$, indicating a $47.37 \%$ overlap in the P50 $\mathrm{S} 2 / \mathrm{S} 1$ ratio between schizophrenia patients and healthy controls. There was also a lack of homogeneity across the 58 comparisons among the 35 articles, Cochrane $\mathrm{Q}=368.74, \quad p<.0005$, $\mathrm{I}^{2}=84.54 \%$. The funnel plot of the $\mathrm{S} 2 / \mathrm{S} 1$ ratio (see Figure 4 ) displayed a clear asymmetric pattern, suggesting a publication bias against findings of small or absent effects.

\section{Examination of Heterogeneity in S1 Amplitude, S2 Amplitude, and P50 S2/S1 Ratio}

To investigate possible sources for the heterogeneity of the S1 amplitude, S2 amplitude, and P50 S2/S1 ratio between schizophrenia patients and healthy controls, we stratified the comparison by research groups (assessing the impact of different protocols, such as Colorado group, as was done in two of the three prior meta-analyses: de Wilde et al., 2007a; Patterson et al., 2008) and limited the analysis to one comparison from each publication. In addition, we investigated whether use of blinding to diagnostic group when measuring P50 amplitude or type of medication for the patients with schizophrenia were potential sources for the heterogeneity. As the research group and blinding were the only moderators to have a more than $10 \%$ effect on the effect sizes, Table 3 presents the results of the effect sizes (the same random effects weighted procedure), Cochrane Q, and $\mathrm{I}^{2}$ for the S2/S1 ratio and the S1 and S2 amplitudes for these moderators. The results showed that larger values of the effect sizes were obtained from the Colorado group than those from other research groups. However, regardless of the research group, the effect size for S1 amplitude was smaller than that for S2 amplitude or for the P50 S2/S1 ratio. 
Table 1. Means (Standard Deviations) of Both S1 and S2 Amplitudes (in $\mu$ V) and P50 S2/S1 Ratios for Both Schizophrenia Patients and Healthy Controls in Each Study

\begin{tabular}{|c|c|c|c|c|}
\hline Study & Number of subjects in data analysis & S1 amplitude & S2 amplitude & $\mathrm{S} 2 / \mathrm{S} 1$ ratio \\
\hline \multirow[t]{5}{*}{ Adler et al. (2004) } & 177 healthy controls & $3.00 \pm 1.50$ & $0.60 \pm 0.07$ & $0.198 \pm 0.210$ \\
\hline & 132 schizophrenia patients (all) & $2.40 \pm 1.80$ & $1.70 \pm 1.70$ & $0.789 \pm 0.646$ \\
\hline & 88 schizophrenia patients (atypical antipsychotic) & $2.20 \pm 1.40$ & $1.40 \pm 1.20$ & $0.704 \pm 0.537$ \\
\hline & 34 schizophrenia patients (typical antipsychotic) & $2.70 \pm 2.60$ & $2.30 \pm 2.70$ & $1.1101 \pm 0.879$ \\
\hline & 10 schizophrenia patients (no medication) & $3.10 \pm 1.70$ & $2.10 \pm 1.40$ & $0.741 \pm 0.278$ \\
\hline \multirow{2}{*}{ Arnfred et al. (2003) } & 22 healthy controls & $2.52 \pm 1.39$ & $1.01 \pm 0.84$ & $0.40 \pm 0.30$ \\
\hline & 12 schizophrenia patients & $2.56 \pm 1.63$ & $0.89 \pm 0.71$ & $0.32 \pm 0.24$ \\
\hline \multirow[t]{3}{*}{ Becker et al. (2004) } & 25 healthy controls & $5.44 \pm 2.72$ & $2.23 \pm 1.78$ & $0.44 \pm 0.27$ \\
\hline & 25 schizophrenia patients (atypical antipsychotic) & $6.39 \pm 3.96$ & $3.73 \pm 4.18$ & $0.57 \pm 0.41$ \\
\hline & 25 schizophrenia patients (typical antipsychotic) & $4.34 \pm 2.70$ & $2.94 \pm 1.41$ & $0.82 \pm 0.45$ \\
\hline \multirow[t]{3}{*}{ Boutros et al. (1991) } & 13 healthy controls & $5.93 \pm 3.08$ & $2.89 \pm 1.39$ & $0.52 \pm 0.15$ \\
\hline & 13 paranoid schizophrenia patients (typical antipsychotic) & $4.05 \pm 2.30$ & $2.37 \pm 1.60$ & $0.59 \pm 0.22$ \\
\hline & 13 undifferentiated schizophrenia patients (typical antipsychotic) & $2.93 \pm 1.92$ & $2.91 \pm 1.09$ & $1.26 \pm 0.71$ \\
\hline \multirow[t]{2}{*}{ Boutros and Belger (1999) } & 12 healthy controls & $3.30 \pm 2.10$ & $1.00 \pm 0.08$ & $0.51 \pm 0.44$ \\
\hline & 12 schizophrenia patients (typical antipsychotic) & $2.50 \pm 1.80$ & $3.30 \pm 1.90$ & $1.42 \pm 0.58$ \\
\hline \multirow{2}{*}{ Boutros et al. (2004) } & 23 healthy controls & $2.60 \pm 2.30$ & $1.30 \pm 1.40$ & $0.54 \pm 0.38$ \\
\hline & 23 schizophrenia patients (atypical antipsychotic) & $2.60 \pm 1.60$ & $2.00 \pm 1.90$ & $0.80 \pm 0.69$ \\
\hline \multirow{4}{*}{ Boutros et al. (2009) } & 31 healthy controls - Mean of all days base-to-peak measure & $3.10 \pm 2.20$ & $1.20 \pm 1.20$ & $0.41 \pm 0.33$ \\
\hline & $\begin{array}{l}35 \text { schizophrenia patients (atypical antipsychotic) - Mean of all days } \\
\text { base-to-peak measure }\end{array}$ & $2.30 \pm 2.40$ & $1.80 \pm 2.60$ & $0.79 \pm 0.53$ \\
\hline & $\begin{array}{l}36 \text { healthy controls - Mean of all days peak-to-peak measure (for } \\
\text { T/C ratio: } 35 \text { healthy controls) }\end{array}$ & $2.80 \pm 2.50$ & $1.40 \pm 1.50$ & $0.67 \pm 0.60$ \\
\hline & $\begin{array}{l}35 \text { schizophrenia patients (atypical antipsychotic) - Mean of all days } \\
\text { peak-to-peak measure }\end{array}$ & $2.90 \pm 2.70$ & $2.00 \pm 2.00$ & $0.79 \pm 0.65$ \\
\hline \multirow[t]{2}{*}{ Brenner et al. (2009) } & 19 healthy controls & $4.62 \pm 2.58$ & $0.94 \pm 0.89$ & $0.94 \pm 2.54$ \\
\hline & 18 schizophrenia patients (medicated) & $4.28 \pm 2.46$ & $2.35 \pm 2.11$ & $0.73 \pm 0.71$ \\
\hline \multirow{2}{*}{$\begin{array}{l}\text { Brockhaus-Dumke, Mueller } \\
\text { et al. (2008a) }\end{array}$} & 32 healthy controls & $3.90 \pm 2.25$ & $1.83 \pm 1.44$ & $0.4019 \pm 0.3862$ \\
\hline & 32 schizophrenia patients & $3.46 \pm 2.63$ & $1.75 \pm 1.41$ & $0.6877 \pm 0.5613$ \\
\hline \multirow[t]{3}{*}{$\begin{array}{l}\text { Brockhaus-Dumke, } \\
\quad \text { Schultz-Lutter et al. (2008b) }\end{array}$} & $\begin{array}{l}41 \text { healthy controls (for } \mathrm{S} 2 \text { amplitude and } \mathrm{T} / \mathrm{C} \text { ratio: } 35 \text { healthy } \\
\text { controls) }\end{array}$ & $3.12 \pm 1.50$ & $1.44 \pm 1.06$ & $0.43 \pm 0.28$ \\
\hline & $\begin{array}{l}14 \text { chronic schizophrenia patients (for } \mathrm{S} 2 \text { amplitude: } 13 \text { chronic } \\
\text { schizophrenia patients; for } \mathrm{T} / \mathrm{C} \text { ratio: } 12 \text { chronic schizophrenia } \\
\text { patients) }\end{array}$ & $2.00 \pm 0.84$ & $1.89 \pm 1.39$ & $0.85 \pm 0.42$ \\
\hline & $\begin{array}{l}29 \text { schizophrenia patients (antipsychotic-naive) (for } \mathrm{S} 2 \text { amplitude and } \\
\mathrm{T} / \mathrm{C} \text { ratio: } 21 \text { schizophrenia patients) }\end{array}$ & $3.14 \pm 1.75$ & $1.96 \pm 1.32$ & $0.65 \pm 0.38$ \\
\hline \multirow[t]{2}{*}{ Clementz et al. (1998a) } & 36 healthy controls & $4.23 \pm 1.33$ & $0.95 \pm 1.01$ & $0.231 \pm 0.222$ \\
\hline & 36 schizophrenia patients ( 28 medicated; 8 unmedicated) & $3.50 \pm 1.26$ & $1.99 \pm 1.23$ & $0.612 \pm 0.465$ \\
\hline \multirow[t]{2}{*}{ Clementz et al. (1998b) } & 45 healthy controls & $4.16 \pm 1.20$ & $1.21 \pm 0.97$ & $0.299 \pm 0.228$ \\
\hline & 44 schizophrenia patients (medicated) & $3.35 \pm 1.14$ & $1.88 \pm 0.92$ & $0.594 \pm 0.316$ \\
\hline \multirow{2}{*}{$\begin{array}{l}\text { Clementz and Blumenfeld } \\
\text { (2001) }\end{array}$} & 20 healthy controls & $2.30 \pm 0.80$ & $0.80 \pm 0.50$ & $0.38 \pm 0.24$ \\
\hline & 20 schizophrenia patients (14 atypical, 6 typical antipsychotic) & $1.80 \pm 0.80$ & $0.80 \pm 0.50$ & $0.48 \pm 0.27$ \\
\hline Devrim-Üçok et al. (2008) & 24 healthy controls & $3.89 \pm 2.00$ & $1.97 \pm 1.34$ & $0.59 \pm 0.44$ \\
\hline & 16 acute schizophrenia patients (medicated) & $2.91 \pm 2.37$ & $2.33 \pm 1.24$ & $0.96 \pm 0.58$ \\
\hline & 16 post-acute schizophrenia patients (medicated) & $3.08 \pm 1.52$ & $1.47 \pm 0.96$ & $0.60 \pm 0.49$ \\
\hline de Wilde et al. (2007b) & 28 healthy controls & $2.02 \pm 1.20$ & $0.93 \pm 1.01$ & $0.4313 \pm 0.3822$ \\
\hline & 27 healthy siblings of schizophrenia patients & $2.18 \pm 1.44$ & $0.82 \pm 0.77$ & $0.4164 \pm 0.4215$ \\
\hline & 53 inpatient schizophrenia patients (medicated) & $2.05 \pm 1.41$ & $1.11 \pm 1.05$ & $0.6502 \pm 0.5582$ \\
\hline Fresán et al. (2007) & 17 healthy controls & $3.00 \pm 2.00$ & $1.00 \pm 0.90$ & $0.30 \pm 0.10$ \\
\hline & 14 violent schizophrenia patients (unmedicated) & $3.80 \pm 2.00$ & $2.90 \pm 1.70$ & $1.00 \pm 0.80$ \\
\hline & 18 nonviolent schizophrenia patients (unmedicated) & $2.70 \pm 2.00$ & $1.70 \pm 1.20$ & $1.00 \pm 1.30$ \\
\hline Ghisolfi et al. (2004) & 24 healthy controls & $5.40 \pm 2.94$ & $2.00 \pm 0.98$ & $0.444 \pm 0.235$ \\
\hline & 12 schizophrenia patients & $4.10 \pm 1.73$ & $3.20 \pm 1.04$ & $0.883 \pm 0.436$ \\
\hline Ghisolfi et al. (2006) & 28 healthy controls & $5.60 \pm 2.90$ & $2.10 \pm 1.10$ & $0.454 \pm 0.209$ \\
\hline & 28 schizophrenia patients (medicated) & $5.20 \pm 3.10$ & $3.30 \pm 1.80$ & $0.792 \pm 0.373$ \\
\hline Guterman and Josiassen & 10 healthy controls & $5.51 \pm 3.18$ & $1.75 \pm 1.28$ & $0.37 \pm 0.28$ \\
\hline (1994) & 10 schizophrenia patients & $4.93 \pm 4.02$ & $2.81 \pm 2.05$ & $1.25 \pm 2.26$ \\
\hline Hong et al. (2004) & 16 healthy controls & $3.00 \pm 1.60$ & $1.10 \pm 0.90$ & $0.39 \pm 0.34$ \\
\hline & 23 schizophrenia patients (medicated) & $3.30 \pm 2.20$ & $1.80 \pm 1.10$ & $0.65 \pm 0.39$ \\
\hline Hong et al. (2008) & 70 healthy controls & $4.04 \pm 3.10$ & $2.01 \pm 1.67$ & $0.56 \pm 0.33$ \\
\hline & 74 healthy relatives of schizophrenia patients & $3.31 \pm 2.75$ & $2.01 \pm 2.41$ & $0.60 \pm 0.34$ \\
\hline & 102 schizophrenia patients (medicated) & $3.91 \pm 3.53$ & $2.32 \pm 2.83$ & $0.62 \pm 0.30$ \\
\hline Hong et al. (2009) & 62 healthy controls & $2.50 \pm 1.47$ & $1.45 \pm 1.18$ & $0.4122 \pm 0.3382$ \\
\hline & 65 schizophrenia patients (baseline) & $2.27 \pm 1.34$ & $1.95 \pm 1.12$ & $0.9419 \pm 0.6131$ \\
\hline & 65 schizophrenia patients (atypical antipsychotic after baseline) & $2.04 \pm 1.13$ & $1.64 \pm 1.07$ & $0.8481 \pm 0.5538$ \\
\hline Jin et al. (1997) & 10 healthy controls & $5.60 \pm 2.97$ & $2.19 \pm 1.80$ & $0.37 \pm 0.20$ \\
\hline & 10 schizophrenia patients (medication-free for 5 days) & $3.34 \pm 1.74$ & $2.34 \pm 1.74$ & $0.73 \pm 0.35$ \\
\hline Johannesen et al. (2005) & 38 healthy controls & $2.14 \pm 0.64$ & $1.19 \pm 0.65$ & $0.5757 \pm 0.3314$ \\
\hline & 37 schizophrenia patients (all; medicated) & $1.87 \pm 0.54$ & $1.25 \pm 0.56$ & $0.6899 \pm 0.3081$ \\
\hline & 11 nonparanoid schizophrenia patients (medicated) & $1.99 \pm 0.44$ & $1.36 \pm 0.42$ & $0.6873 \pm 0.1868$ \\
\hline & 26 paranoid schizophrenia patients (medicated) & $1.83 \pm 0.57$ & $1.20 \pm 0.61$ & $0.6910 \pm 0.3503$ \\
\hline Kathmann and Engel (1990) & 22 healthy controls & $3.00 \pm 1.41$ & $2.10 \pm 0.94$ & $0.73 \pm 0.39$ \\
\hline & 18 schizophrenia patients (medicated) & $2.60 \pm 0.85$ & $2.10 \pm 1.70$ & $0.947 \pm 0.82$ \\
\hline Kisley et al. (2003) & 10 healthy controls, non-REM & $1.51 \pm 0.62$ & $0.67 \pm 0.81$ & $0.39 \pm 0.35$ \\
\hline & 10 healthy controls, REM & $0.79 \pm 0.29$ & $0.18 \pm 0.18$ & $0.20 \pm 0.22$ \\
\hline
\end{tabular}


Table 1. (Contd.)

\begin{tabular}{|c|c|c|c|c|}
\hline Study & Number of subjects in data analysis & S1 amplitude & S2 amplitude & $\mathrm{S} 2 / \mathrm{S} 1$ ratio \\
\hline & 10 schizophrenia patients (medicated), non-REM & $1.63 \pm 1.27$ & $1.85 \pm 2.58$ & $0.93 \pm 0.66$ \\
\hline & 10 schizophrenia patients (medicated), REM & $1.40 \pm 1.02$ & $1.31 \pm 1.36$ & $0.93 \pm 0.73$ \\
\hline$(2005)$ & 26 negative symptom schizophrenia patients (atypical antipsychotic) & $3.31 \pm 2.70$ & $2.48 \pm 1.50$ & $0.97 \pm 0.60$ \\
\hline & $\begin{array}{l}55 \text { no negative symptom schizophrenia patients (atypical } \\
\text { antipsychotic) }\end{array}$ & $3.60 \pm 2.60$ & $2.78 \pm 2.20$ & $0.80 \pm 0.40$ \\
\hline \multirow[t]{3}{*}{ Martin et al. (2007) } & 108 healthy controls (common gene) & $3.10 \pm 1.70$ & $0.60 \pm 0.70$ & $0.17 \pm 0.15$ \\
\hline & 26 schizophrenia patients (common gene) & $2.10 \pm 0.90$ & $1.80 \pm 0.90$ & $1.01 \pm 0.63$ \\
\hline & 11 schizophrenia patients (variant gene) & $2.20 \pm 1.50$ & $2.10 \pm 1.50$ & $1.11 \pm 0.72$ \\
\hline \multirow[t]{3}{*}{ Myles-Worsley (2002) } & 29 healthy controls & $2.96 \pm 1.59$ & $0.88 \pm 0.74$ & $0.307 \pm 0.227$ \\
\hline & 29 schizophrenia patients (unmedicated) & $1.75 \pm 1.40$ & $0.98 \pm 0.97$ & $0.716 \pm 0.598$ \\
\hline & 56 schizophrenia patients (medicated) & $2.04 \pm 1.14$ & $1.42 \pm 1.14$ & $0.745 \pm 0.477$ \\
\hline \multirow[t]{2}{*}{ Olincy et al. (2000) } & 16 healthy controls & $2.61 \pm 1.57$ & $0.50 \pm 0.65$ & $0.1622 \pm 0.1210$ \\
\hline & 16 schizophrenia patients & $2.53 \pm 1.58$ & $1.53 \pm 0.85$ & $0.6701 \pm 0.1346$ \\
\hline \multirow[t]{2}{*}{ Patterson et al. (2000) } & 10 healthy controls & $4.14 \pm 2.69$ & $1.71 \pm 1.93$ & $0.36 \pm 0.25$ \\
\hline & 10 schizophrenia patients & $2.57 \pm 1.80$ & $2.03 \pm 1.64$ & $1.18 \pm 1.49$ \\
\hline \multirow{2}{*}{ Rentzsch et al. (2007) } & 12 schizophrenia patients without cannabis abuse & $3.90 \pm 3.10$ & $1.40 \pm 0.90$ & $0.366 \pm 0.177$ \\
\hline & 15 schizophrenia patients with cannabis abuse & $2.80 \pm 1.40$ & $1.30 \pm 0.70$ & $0.477 \pm 0.194$ \\
\hline \multirow[t]{2}{*}{ Sánchez-Morla et al. (2008) } & 63 healthy controls & $3.90 \pm 2.10$ & $1.70 \pm 1.30$ & $0.41 \pm 0.23$ \\
\hline & 90 schizophrenia patients & $4.40 \pm 2.80$ & $2.70 \pm 1.90$ & $0.67 \pm 0.33$ \\
\hline \multirow[t]{4}{*}{ Sánchez-Morla et al. (2009) } & 64 healthy controls & $3.91 \pm 2.14$ & $1.68 \pm 1.26$ & $0.428 \pm 0.255$ \\
\hline & 42 schizophrenia patients (medicated: CLZ) & $4.90 \pm 2.94$ & $2.75 \pm 1.71$ & $0.600 \pm 0.258$ \\
\hline & 47 schizophrenia patients (medicated: FGAs) & $4.76 \pm 2.48$ & $3.07 \pm 1.70$ & $0.700 \pm 0.332$ \\
\hline & 65 schizophrenia patients (medicated: SGAs) & $4.18 \pm 2.33$ & $2.59 \pm 1.78$ & $0.681 \pm 0.375$ \\
\hline \multirow[t]{2}{*}{ Yee et al. (1998) } & 11 healthy controls & $3.44 \pm 2.38$ & $1.36 \pm 0.99$ & $0.38 \pm 0.18$ \\
\hline & 22 recent-onset schizophrenia patients (medicated) & $3.18 \pm 2.26$ & $1.81 \pm 1.63$ & $0.59 \pm 0.33$ \\
\hline
\end{tabular}

\section{Discussion}

This meta-analysis specifically addresses the relative importance of measuring S2 amplitude and the ratio measure of sensory gating compared to only measuring S1 amplitude in people with schizophrenia. This meta-analysis builds upon previously published meta-analyses by investigating the differences in the P50 amplitudes and gating ratios between schizophrenia patients and healthy controls by including studies published since the publication of the last meta-analysis (Patterson et al., 2008). The number of new studies was 18 in just 2 years, underscoring the significant interest of investigators in the gating function. The findings clearly show increasing effect size corresponding to additional information. The effect size was small for the S1 amplitude difference, increased to a medium to large effect size of the S2 amplitude difference, and finally a large effect size of the S2/S1 ratio between schizophrenia patients and healthy controls.

Together, these findings suggest that sensory gating deficit of the P50 (S2/S1 ratio) in schizophrenia patients as compared to healthy controls may be more pertinent to the degree of change in brain response from $\mathrm{S} 1$ to $\mathrm{S} 2$ stimuli between healthy controls and schizophrenia than just measuring the $\mathrm{S} 1$ stimuli. However, although the $\mathrm{S} 2 / \mathrm{S} 1$ gating ratio is a dominant measure in the literature, it may not be the best approach to summarizing sensory gating deficit in schizophrenia, and exploration of different approaches, such as the S1-S2 amplitude difference, may be worthwhile.

Our estimates of the effect sizes for S1 amplitude and S2/S1 ratio are remarkably similar to previous meta-analyses (Patterson et al., 2008), indicating that, although the number of studies has increased dramatically and the subtypes of patients have narrowed, the finding of a larger effect size for S2 amplitude than that of S1 amplitude appears valid. There is heterogeneity in the effect size, which is partially related to research groups as previously shown (Patterson et al., 2008). Unfortunately for $\mathrm{S} 2 / \mathrm{S} 1$ ratio, there appears to be a publication bias with large negative studies not being submitted or accepted for publication.

\section{Difference in the S1 Amplitude}

The mean S1 amplitudes of schizophrenia patients and healthy controls exhibited a wide range of values and a high percentage of overlapping, yielding a small combined effect size. In $65.52 \%$ of the comparisons, the schizophrenia group had a lower mean S1 amplitude than the control group. These findings were similar to the previous meta-analysis (Patterson et al., 2008) in which they rejected zero difference in the $\mathrm{S} 1$ amplitude between schizophrenia patients and normal controls, but 25 of the 37 studies overlapped the zero difference. We thus can conclude that the noted deficit in habituation or gating of the responses to S2 stimuli across studies and comparisons is not predicated on a failure to register the $\mathrm{S} 1$ stimuli in schizophrenia patients as the effect size of S2 amplitude and S2/S1 ratio are much larger. However, this conclusion is not in line with Jansen et al. (2004) and Brenner et al. (2009), which proposed that sensory gating deficit in schizophrenia patients is due to the problem in evaluating stimulus in the sensory encoding and, consequently, a failure in responding to and detecting the salient information of the S1.

These summary findings across published articles corroborate the finding at the individual participant level (e.g., Fuerst et al., 2007). Fuerst et al. (2007) demonstrated that the $\mathrm{S} 1$ amplitude does not correlate with the gating ratio nor significantly predict the gating ratio in a sample of healthy controls. In addition, data from schizophrenia patients were in fundamental agreement with healthy control data (Boutros et al., 2009). Furthermore, this S1 amplitude finding is in line with the results from Jin et al. (1997) and Clementz et al. (1997). However, whether the P50 S1 amplitude is a candidate for a schizophrenia endophenotype 
remains an open question (Patterson et al., 2008). More research, thus, is still needed in order to better elucidate the exact contribution of the $\mathrm{S} 1$ in the $\mathrm{P} 50$ gating process in schizophrenia.

Difference in the S2 Amplitude- "Gating Out"

The present study was the first to systematically investigate the S2 difference between schizophrenia patients and healthy controls, which the previous meta-analyses did not address. In the current meta-analysis, the medium effect size indicates that the ability to suppress redundant stimuli is deficient consistently in schizophrenia patients as compared to healthy controls and would require fewer patients to detect such a deficiency than using only S1.

When examining the effect sizes of the $\mathrm{S} 2$ amplitude and the P50 S2/S1 ratio, we speculate that, across studies, the difference in sensory gating ability between healthy controls and schizophrenia patients may possibly be associated with the difference in brain response to the $\mathrm{S} 2$ stimulus, as the effect size of the $\mathrm{S} 2$ amplitude was medium to large and the $\mathrm{S} 2 / \mathrm{S} 1$ ratio was large. Based on these effect size results, we further conjecture that, at the group level, sensory gating deficit in schizophrenia patients may result from the inability to suppress the $\mathrm{S} 1$ response with

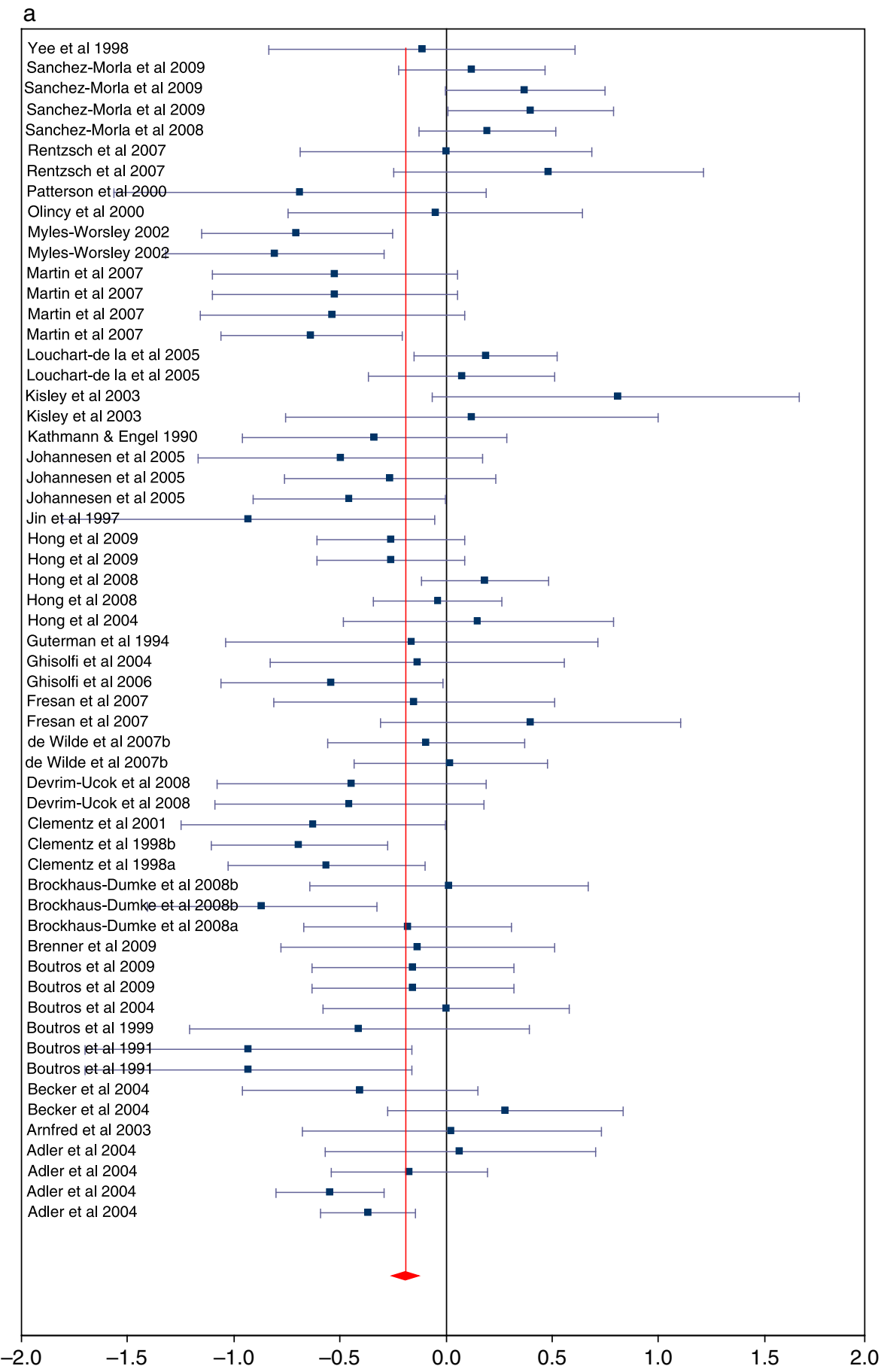

Figure 1a, 1b, and 1c. Forest plots of effect sizes of the S1 amplitude, S2 amplitude, and S2/S1 ratio from weighted random effects model. 


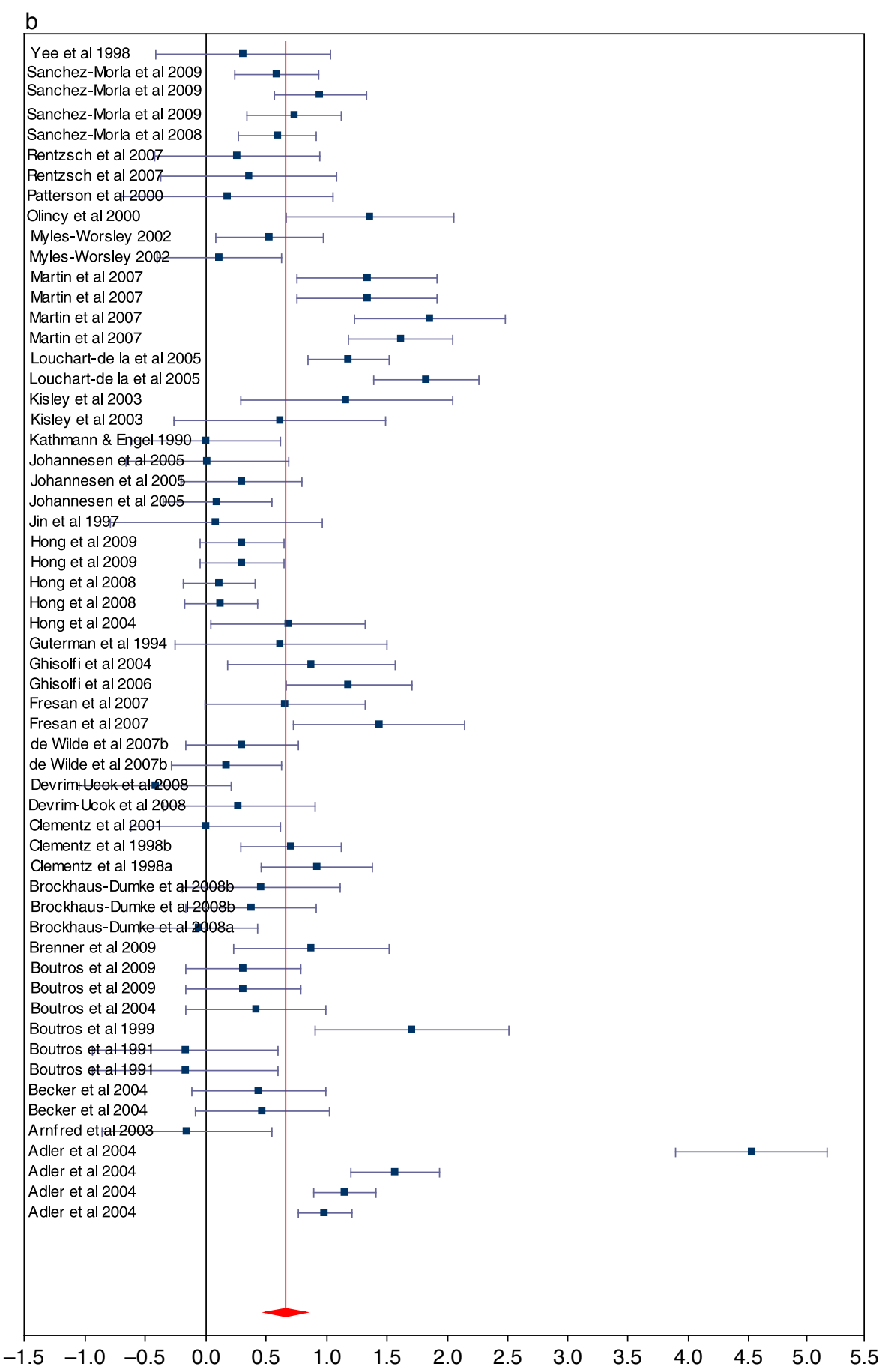

Figure 1. Continued.

repetition as assessed by measuring the $\mathrm{S} 2$ response. However, this inference needs further investigation with large individual patient data.

Investigators disagree on the mechanism of the deficient sensory gating. It has been argued that it is due to a neural malfunction of inhibitory mechanism responsible for "gating out" discarded information (Clementz et al., 1997; Freedman et al., 1987). It has also been argued that it is a failure of neural mechanism responsible for registering salient information (Jansen et al., 2004). Finally, it has been argued that it is due to an unusually small S1 response accompanied with an otherwise typical S2 response (Blumenfeld \& Clementz, 2001; Johannesen et al., 2005). The findings of the current meta-analysis provide support for the argument that poor sensory gating in schizophrenia patients is a large effect in the published studies and thus "gating out" redundant and irrelevant sensory information.

Difference in the P50 S2/S1 Ratio

The results showed that schizophrenia patients exhibited a larger $\mathrm{S} 2 / \mathrm{S} 1$ ratio than healthy controls and the effect size for the S2/S1 ratio was large, which was consistent with the findings from previous three meta-analyses (Bramon et al., 2004; de Wilde et al., 


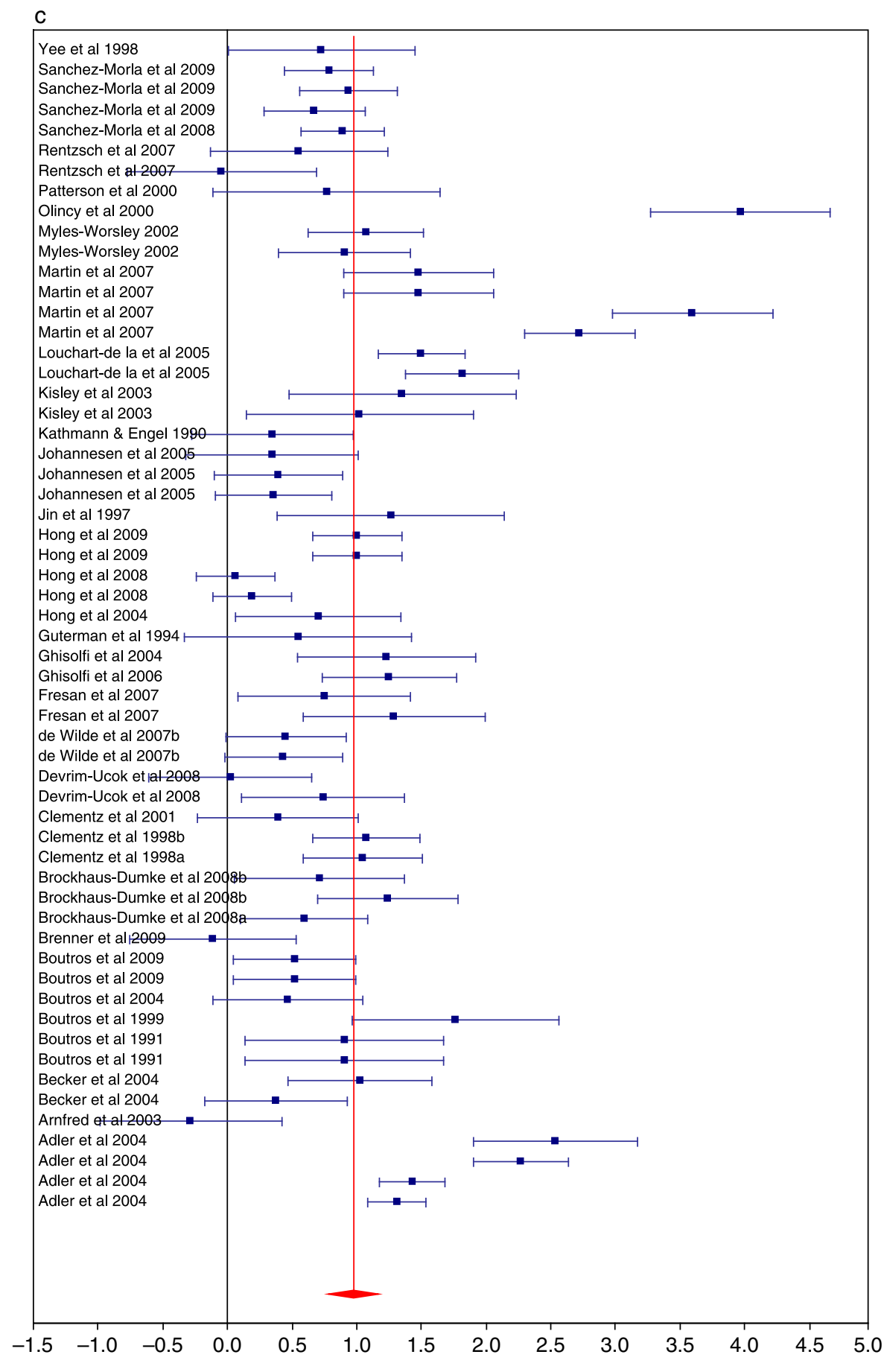

Figure 1. Continued.

2007a; Patterson et al., 2008). In addition, there was an overlap in the P50 S2/S1 ratio between healthy controls and schizophrenia patients, similar to Patterson et al. (2008), and the range of the effect size was similar to the previous three meta-analyses.

To investigate the heterogeneity in the $\mathrm{P} 50 \mathrm{~S} 2 / \mathrm{S} 1$ ratio, different moderators have been addressed in the previous metaanalyses (Bramon et al., 2004; de Wilde et al., 2007a; Patterson et al., 2008). For example, Bramon et al. (2004) found that age, gender, and filter setting could not explain the observed variability of the effect size in the P50 ratio and suggested that these parameters contribute similar effects to healthy controls. When other sources of heterogeneity were examined, studies from one research group (i.e., Colorado) displayed a larger effect size than those from other research groups. It is reassuring that the inclusion of 18 more recent studies did not alter this finding, which remains consistent with that of de Wilde et al. (2007a).

Patterson et al. (2008) suggested that methodological issues, such as filter settings, click intensity, and blinding the P50 measurement, need to be considered when analyzing $\mathrm{P} 50 \mathrm{~S} 2 / \mathrm{S} 1$ ratio data. When we examined the blinding issue in the $\mathrm{S} 2 / \mathrm{S} 1$ ratio, studies using the blinding procedure revealed a medium to large effect size, whereas studies with no blinding procedure showed a 
Table 2. Effect Side (Cohen's d) of S1 Amplitude, S2 Amplitude and P50 S2/S1 Ratio for Each Comparison Among 35 Publications

\begin{tabular}{|c|c|c|c|c|}
\hline Study & Comparison & $\begin{array}{l}\text { S1 amplitude } \\
(95 \% \text { Interval })\end{array}$ & $\begin{array}{l}\text { S2 amplitude } \\
\text { (95\% Interval) }\end{array}$ & $\begin{array}{l}\mathrm{S} 2 / \mathrm{S} 1 \text { ratio } \\
(95 \% \text { Interval })\end{array}$ \\
\hline \multirow[t]{5}{*}{ Adler et al. (2004) } & 132 schizophrenia patients (all) vs. 177 healthy controls & $\begin{array}{c}-0.37 \\
(-0.60--0.14)\end{array}$ & $\begin{array}{c}0.99 \\
(0.75-1.23)\end{array}$ & $\begin{array}{c}1.31 \\
(1.07-1.56)\end{array}$ \\
\hline & 88 schizophrenia patients (atypical antipsychotic) vs. 177 healthy controls & $\begin{array}{c}-0.55 \\
(-0.81--0.29)\end{array}$ & $\begin{array}{c}1.16 \\
(0.89-1.43)\end{array}$ & $\begin{array}{c}1.44 \\
(1.15-1.72)\end{array}$ \\
\hline & 34 schizophrenia patients (typical antipsychotic) vs. 177 healthy controls & -0.18 & 1.59 & 2.30 \\
\hline & & $(-0.54-0.19)$ & $(1.19-1.99)$ & $(1.87-3.24)$ \\
\hline & & $\left(-0.5^{\prime}\right.$ & $(3.89$ & $(2.37$ \\
\hline \multirow[t]{2}{*}{ Arnfred et al. (2003) } & 12 schizophrenia patients vs. 22 healthy controls & 0.03 & -0.16 & -0.29 \\
\hline & & $(-0.68-0.73)$ & $(-0.86-0.55)$ & $(-1.00-0.41)$ \\
\hline \multirow[t]{4}{*}{ Becker et al. (2004) } & 25 schizophrenia patients (atypical antipsychotic) vs. 25 healthy controls & 0.29 & 0.48 & 0.38 \\
\hline & & $(-0.27-0.84)$ & $(-0.09-1.04)$ & $(-0.18-0.94)$ \\
\hline & 25 schizophrenia patients (typical antipsychotic) vs. 25 healthy controls & -0.41 & 0.45 & 1.05 \\
\hline & & $(-0.97-0.15)$ & $(-0.11-1.01)$ & $(0.45-1.64)$ \\
\hline \multirow[t]{2}{*}{ Boutros et al. (1991) } & 13 paranoid schizophrenia patients (typical antipsychotic) vs. 13 healthy & -0.69 & -0.35 & 0.37 \\
\hline & healthy controls & $(-1.94-0.40)$ & $(-0.75-0.78)$ & $(0.67-2.21)$ \\
\hline $\begin{array}{l}\text { Boutros and Belger } \\
\text { (1999) }\end{array}$ & 12 schizophrenia patients (typical antipsychotic) vs. 12 healthy controls & $\begin{array}{c}-0.41 \\
(-1.21-0.39)\end{array}$ & $\begin{array}{c}1.71 \\
(0.91-2.51)\end{array}$ & $\begin{array}{c}1.77 \\
(0.97-2.57)\end{array}$ \\
\hline \multirow[t]{2}{*}{ Boutros et al. (2004) } & 23 schizophrenia patients (atypical antipsychotic) vs. 23 healthy controls & 0 & 0.42 & 0.47 \\
\hline & & $(-0.58-0.58)$ & $(-0.16-1.00)$ & $(-0.11-1.04)$ \\
\hline \multirow[t]{5}{*}{ Boutros et al. (2009) } & Mean of all days base-to-peak measure: & -0.35 & 0.29 & 0.85 \\
\hline & 35 schizophrenia patients (atypical antipsychotic) vs. 31 healthy controls & $(-0.83-0.14)$ & $(-0.19-0.77)$ & $(0.37-1.33)$ \\
\hline & & 0.04 & 0.34 & 0.19 \\
\hline & Mean of all days peak-to-peak measure: & $(-0.43-0.50)$ & $(-0.13-0.81)$ & $(-0.27-0.66)$ \\
\hline & $\begin{array}{l}35 \text { schizophrenia patients (atypical antipsychotic) vs. } 36 \text { healthy controls (for } \mathrm{T} / \mathrm{C} \text { ratio: } \\
35 \text { healthy controls) }\end{array}$ & -0.14 & 0.90 & -0.11 \\
\hline Brenner et al. (2009) & 18 schizophrenia patients (medicated) vs. 19 healthy controls & $(-0.78-0.51)$ & $(0.23-1.58)$ & $(-0.76-0.53)$ \\
\hline \multirow{2}{*}{$\begin{array}{l}\text { Brockhaus-Dumke } \\
\text { et al. }(2008 \mathrm{a})\end{array}$} & 32 schizophrenia patients vs. 32 healthy controls & -0.18 & -0.06 & 0.60 \\
\hline & & $(-0.67-0.31)$ & $(-0.54-0.43)$ & $(0.10-1.14)$ \\
\hline \multirow{3}{*}{$\begin{array}{l}\text { Brockhaus-Dumke } \\
\text { et al. }(2008 \mathrm{~b})\end{array}$} & 14 chronic schizophrenia patients (for S2 amplitude: 13 chronic schizophrenia patients; & -0.88 & 0.38 & 1.26 \\
\hline & $\begin{array}{l}\text { for } \mathrm{T} / \mathrm{C} \text { ratio: } 12 \text { chronic schizophrenia patients) vs. } 41 \text { healthy controls } \\
\text { (for } \mathrm{S} 2 \text { amplitude and } \mathrm{T} / \mathrm{C} \text { ratio: } 35 \text { healthy controls) }\end{array}$ & $(-1.45--0.31)$ & $(-0.16-0.93)$ & $(0.67-1.85)$ \\
\hline & 29 schizophrenia patients (antipsychotic-naive) (for S2 amplitude and T/C ratio: 21 & 0.01 & 0.47 & 0.73 \\
\hline \multirow{4}{*}{$\begin{array}{l}\text { Clementz et al. } \\
\quad(1998 \mathrm{a}) \\
\text { Clementz et al. }\end{array}$} & 36 schizophrenia patients ( 28 medicated; 8 unmedicated) vs. 36 healthy controls & -0.70 & 0.92 & 1.05 \\
\hline & & $(-1.18--0$. & $(0.46-1.39)$ & $(0.58-1.51)$ \\
\hline & 44 schizophrenia patients (medicated) vs. 45 healthy controls & -0.63 & 0.71 & 1.07 \\
\hline & & $(-1.06--0$. & $(0.29-1.12)$ & $(0.66-1.49)$ \\
\hline \multirow{2}{*}{$\begin{array}{l}\text { Clementz and } \\
\text { Blumenfeld (2001) }\end{array}$} & 20 schizophrenia patients ( 14 atypical, 6 typical antipsychotic) vs. 20 healthy controls & -0.58 & 0 & 0.39 \\
\hline & & $(-1.21-0.06)$ & $(-0.62-0.62)$ & $(-0.23-1.01)$ \\
\hline \multirow{4}{*}{$\begin{array}{l}\text { Devrim-Üçok et al. } \\
\text { (2008) }\end{array}$} & 16 acute schizophrenia patients (medicated) vs. 24 healthy controls & -0.47 & 0.28 & 0.76 \\
\hline & & $(-1.11-0.17)$ & $(-0.35-0.92)$ & $(0.10-1.41)$ \\
\hline & 16 post-acute schizophrenia patients (medicated) vs. 24 healthy controls & -0.46 & -0.42 & 0.02 \\
\hline & & $(-1.10-0.19)$ & $(-1.07-0.21)$ & $(-0.61-0.65)$ \\
\hline \multirow{4}{*}{$\begin{array}{l}\text { de Wilde et al. } \\
\text { (2007b) }\end{array}$} & 53 inpatient schizophrenia patients (medicated) vs. 28 healthy controls & 0.02 & 0.18 & 0.44 \\
\hline & & $(-0.44-0.48)$ & $(-0.28-0.63)$ & $(-0.02-0.90)$ \\
\hline & 53 inpatient schizophrenia patients (medicated) vs. 27 healthy siblings of schizophrenia & -0.09 & 0.30 & 0.46 \\
\hline & & $(-0.57-0.37)$ & $(-0.16-0.77)$ & $(-0.01-0.93)$ \\
\hline \multirow[t]{4}{*}{ Fresán et al. (2007) } & 14 violent schizophrenia patients (unmedicated) vs. 17 healthy controls & 0.41 & 1.49 & 1.34 \\
\hline & & $(-0.30-1.13)$ & $(0.68-2.29)$ & $(0.55-2.13)$ \\
\hline & 18 nonviolent schizophrenia patients (unmedicated) vs. 17 healthy controls & -0.15 & 0.68 & 0.77 \\
\hline & & $(-0.82-0.51)$ & $(-0.01-1.36)$ & $(0.08-1.46)$ \\
\hline Ghisolfi et al. (2004) & 12 schizophrenia patients vs. 24 healthy controls & -0.55 & 0.90 & 1.27 \\
\hline & & $(-1.08--0.01)$ & $(0.18-1.63)$ & $(0.52-2.03)$ \\
\hline Ghisolfi et al. (2006) & 28 schizophrenia patients (medicated) vs. 28 healthy controls & -0.14 & 1.21 & 1.28 \\
\hline & & $(-0.83-0.55)$ & $(0.64-1.78)$ & $(0.70-1.85)$ \\
\hline Guterman and & 10 schizophrenia patients vs. 10 healthy controls & -0.16 & 0.65 & 0.58 \\
\hline Josiassen (1994) & & $(-1.05-0.71)$ & $(-0.25-1.56)$ & $(-0.32-1.47)$ \\
\hline Hong et al. (2004) & 23 schizophrenia patients (medicated) vs. 16 healthy controls & 0.19 & 0.68 & 0.70 \\
\hline & & $(-0.45-0.8$ & $(0.05-1.32)$ & $(0.06-1.34)$ \\
\hline Hong et al. (2008) & 102 schizophrenia patients (medicated) vs. 70 healthy controls & -0.04 & 0.13 & 0.19 \\
\hline & & $(-0.34-0.27)$ & $(-0.18-0.43)$ & $(-0.11-0.50)$ \\
\hline & 102 schizophrenia patients (medicated) vs. 74 healthy relatives of schizophrenic patients & 0.19 & 0.12 & 0.06 \\
\hline & & $(-0.11-0.49)$ & $(-0.18-0.42)$ & $(-0.24-0.36)$ \\
\hline Hong et al. (2009) & 65 schizophrenia patients (baseline) vs. 62 healthy controls & -0.16 & 0.43 & 1.06 \\
\hline & & $(-0.51-0.18)$ & $(0.09-0.78)$ & $(0.72-1.41)$ \\
\hline & 65 schizophrenia patients (atypical antipsychotic after baseline) vs. 62 healthy controls & -0.35 & 0.17 & 0.94 \\
\hline & & $(-0.70-0.004)$ & $(-0.18-0.52)$ & $(0.60-1.29)$ \\
\hline Jin et al. (1997) & 10 schizophrenia patients (medication-free for 5 days) vs. 10 healthy controls & -0.98 & 0.09 & 1.33 \\
\hline & & $(-1.91--0.05)$ & $(-0.79-0.97)$ & $(0.35-2.31)$ \\
\hline
\end{tabular}


Table 2. (Contd.)

\begin{tabular}{|c|c|c|c|c|}
\hline Study & Comparison & $\begin{array}{l}\text { S1 amplitude } \\
\text { (95\% Interval) }\end{array}$ & $\begin{array}{l}\text { S2 amplitude } \\
\text { (95\% Interval) }\end{array}$ & $\begin{array}{c}\mathrm{S} 2 / \mathrm{S} 1 \text { ratio } \\
(95 \% \text { Interval })\end{array}$ \\
\hline \multirow[t]{5}{*}{$\begin{array}{l}\text { Johannesen et al. } \\
\quad(2005)\end{array}$} & 37 schizophrenia patients (all; medicated) vs. 38 healthy controls & $\begin{array}{c}-0.46 \\
(-0.92--0.002)\end{array}$ & $\begin{array}{c}0.10 \\
(-0.35-0.55)\end{array}$ & $\begin{array}{c}0.36 \\
(-0.09-0.82)\end{array}$ \\
\hline & 11 nonparanoid schizophrenia patients (medicated) vs. 38 healthy controls & -0.27 & 0.30 & 0.40 \\
\hline & & $(-0.78-0.23)$ & $(-0.20-0.80)$ & $(-0.10-0.91)$ \\
\hline & 26 paranoid schizophrenia patients (medicated) vs. 38 healthy controls & -0.51 & 0.02 & 0.35 \\
\hline & & $(-1.18-0.17)$ & $(-0.66-0.69$ & $(-0.32-1.03)$ \\
\hline \multirow{2}{*}{$\begin{array}{r}\text { Kathmann and } \\
\text { Engel (1990) }\end{array}$} & 18 schizophrenia patients (medicated) vs. 22 healthy controls & -0.34 & 0 & 0.36 \\
\hline & & $(-0.97-0.28)$ & $(-0.62-0.62)$ & $(-0.27-0.99)$ \\
\hline \multirow[t]{4}{*}{ Kisley et al. (2003) } & 10 schizophrenia patients (medicated) vs. 10 healthy controls, non-REM & 0.13 & 0.65 & 1.08 \\
\hline & & $(-0.75-1.00)$ & $(-0.25-1.55)$ & $(0.13-2.02)$ \\
\hline & 10 schizophrenia patients (medicated) vs. 10 healthy controls, REM & 0.86 & 1.23 & 1.43 \\
\hline & & $(-0.06-1.78)$ & $(0.26-2.19)$ & $(0.43-2.42)$ \\
\hline \multirow{4}{*}{$\begin{array}{l}\text { Louchart-de la } \\
\text { Chapelle et al. } \\
(2005)\end{array}$} & 26 negative symptom schizophrenia patients (atypical antipsychotic) vs. 88 healthy & 0.08 & 1.86 & 1.84 \\
\hline & controls & $(-0.36-0.51)$ & $(1.36-2.36)$ & $(1.34-2.34)$ \\
\hline & 55 no negative symptom schizophrenia patients (atypical antipsychotic) vs. 88 healthy & 0.19 & 1.19 & 1.51 \\
\hline & controls & $(-0.15-0.53)$ & $(0.83-1.55)$ & $(1.13-1.89)$ \\
\hline \multirow[t]{8}{*}{ Martin et al. (2007) } & 26 schizophrenia patients (common gene) vs. 108 healthy controls (common gene) & -0.64 & 1.63 & 2.77 \\
\hline & & $(-1.07--0.20)$ & $(1.16-2.10)$ & $(2.23-3.31)$ \\
\hline & 26 schizophrenia patients (common gene) vs. 41 healthy controls (variant gene) & -0.61 & 1.30 & 1.37 \\
\hline & & $(-1.11--0.11)$ & $(0.76-1.84)$ & $(0.83-1.92)$ \\
\hline & 11 schizophrenia patients (variant gene) vs. 108 healthy controls (common gene) & -0.54 & 1.89 & 3.72 \\
\hline & & $(-1.16-0.09)$ & $(1.22-2.56)$ & $(2.94-4.50)$ \\
\hline & 11 schizophrenia patients (variant gene) vs. 41 healthy controls (variant gene) & -0.46 & 1.44 & 1.65 \\
\hline & & $(-1.13-0.22)$ & $(0.72-2.17)$ & $(0.91-2.39)$ \\
\hline \multirow{4}{*}{$\begin{array}{l}\text { Myles-Worsley } \\
\text { (2002) }\end{array}$} & 29 schizophrenia patients (unmedicated) vs. 29 healthy controls & -0.82 & 0.12 & 0.92 \\
\hline & & $(-1.36--0.28)$ & $(-0.40-0.63)$ & $(0.38-1.46)$ \\
\hline & 56 schizophrenia patients (medicated) vs. 29 healthy controls & -0.71 & 0.53 & 1.08 \\
\hline & & $(-1.17--0.25)$ & $(0.08-0.99)$ & $(0.60-1.56)$ \\
\hline \multirow[t]{2}{*}{ Olincy et al. (2000) } & 16 schizophrenia patients vs. 16 healthy controls & -0.05 & 1.41 & 3.97 \\
\hline & & $(-0.75-0.64)$ & $(0.63-2.18)$ & $(3.28-4.66)$ \\
\hline \multirow{2}{*}{$\begin{array}{l}\text { Patterson et al. } \\
\quad(2000)\end{array}$} & 10 schizophrenia patients vs. 10 healthy controls & -0.72 & 0.19 & 0.81 \\
\hline & & $(-1.63-0.18)$ & $(-0.69-1.07)$ & $(-0.11-1.72)$ \\
\hline \multirow{4}{*}{$\begin{array}{l}\text { Rentzsch et al. } \\
\text { (2007) }\end{array}$} & 12 schizophrenia patients s without cannabis abuse vs. 18 healthy controls & 0.50 & 0.37 & -0.05 \\
\hline & & $(-0.24-1.24)$ & $(-0.37-1.11)$ & $(-0.78-0.68)$ \\
\hline & 15 schizophrenia patients s with cannabis abuse vs. 18 healthy controls & 0 & 0.27 & 0.57 \\
\hline & & $(-0.68-0.68)$ & $(-0.42-0.96)$ & $(-0.13-1.27)$ \\
\hline \multirow{2}{*}{$\begin{array}{l}\text { Sánchez-Morla } \\
\text { et al. (2008) }\end{array}$} & 90 schizophrenia patients vs. 63 healthy controls & 0.20 & 0.60 & 0.89 \\
\hline & & $(-0.12-0.52)$ & $(0.27-0.93)$ & $(0.56-1.23)$ \\
\hline \multirow{6}{*}{$\begin{array}{l}\text { Sánchez-Morla } \\
\text { et al. (2009) }\end{array}$} & 42 schizophrenia patients (medicated: CLZ) vs. 64 healthy controls & 0.40 & .74 & 0.68 \\
\hline & & $(0.01-0.80)$ & $(0.35-1.12)$ & $(0.28-1.08)$ \\
\hline & 47 schizophrenia patients (medicated: FGAs) vs. 64 healthy controls & 0.37 & 0.94 & 0.93 \\
\hline & & $(0.02-0.71)$ & $(0.57-1.30)$ & $(0.56-1.29)$ \\
\hline & 65 schizophrenia patients (medicated: SGAs) vs. 64 healthy controls & 0.12 & 0.59 & 0.79 \\
\hline & & $(-0.25-0.50)$ & $(0.24-0.913$ & $(0.44-1.13)$ \\
\hline \multirow[t]{2}{*}{ Yee et al. (1998) } & 22 recent-onset schizophrenia patients (medicated) vs. 11 healthy controls & -0.12 & 0.32 & 0.75 \\
\hline & & $(-0.84-1.29)$ & $(-0.41-1.05)$ & $(0-1.49)$ \\
\hline
\end{tabular}

large effect size. This finding suggests that blinding impacts the P50 measurement. Whether paying specific attention to methodological issues, such as strict blinded evaluation of the P50 component (Boutros, 2008) and increasing the number of averaged trials in order to improve the SNR, will impact the overall effect size of the P50, gating deficit in schizophrenia remains to be seen. Nonetheless, given the large effect size and the results of moderator analysis consistent with the previous studies, the difference in the P50 S2/S1 ratio between schizophrenia patients and healthy controls is plausible, and schizophrenia patients display a problem in sensory gating compared to healthy controls.

In addition to heterogeneity and methodological issues, our results indicated a publication bias in P50 S2/S1 ratio, which was different from both Bramon et al. (2004) and de Wilde et al. (2007a). This inconsistent finding may be due to the addition of recent studies since the publication of those meta-analyses. There may now be a bias to expect significant difference in P50 S2/S1 ratio between schizophrenia and controls. Although this publication bias may be due to our inclusion/exclusion criteria, this is doubtful as it did not impact our estimates for the S1 amplitude.

\section{Implications for Sensory Gating Research in Schizophrenia}

The findings of this present meta-analysis have two major implications for sensory gating research in schizophrenia patients. First, this study found a small effect size of the S1 amplitude, a between medium and large effect size of the $\mathrm{S} 2$ amplitude, and a large effect size of the P5 S2/S1 ratio. This finding suggests that a large effect size of the P50 S2/S1 ratio and S2 amplitude hold valuable information. In other words, this finding confirms the supposition that, at the group level, when compared to healthy controls sensory gating deficit in schizophrenia patients is potentially caused by an augmentation or a lack of reduction in the $\mathrm{S} 2$ response in contrast to healthy controls, suggesting a "gating out" habituation problem. Our findings suggest that the S2 amplitude is necessary to gauge sensory gating when compared to S1 amplitude and that the measurement of $\mathrm{S} 1$ amplitude alone is not sufficient to predict or assess the difference in gating function between healthy controls and schizophrenia. Also, the measurement of the S2 amplitude is indispensable to calculate the S1-S2 amplitude difference as another sensory gating index (Smith et al., 1994; de Wilde et al., 2007a). 


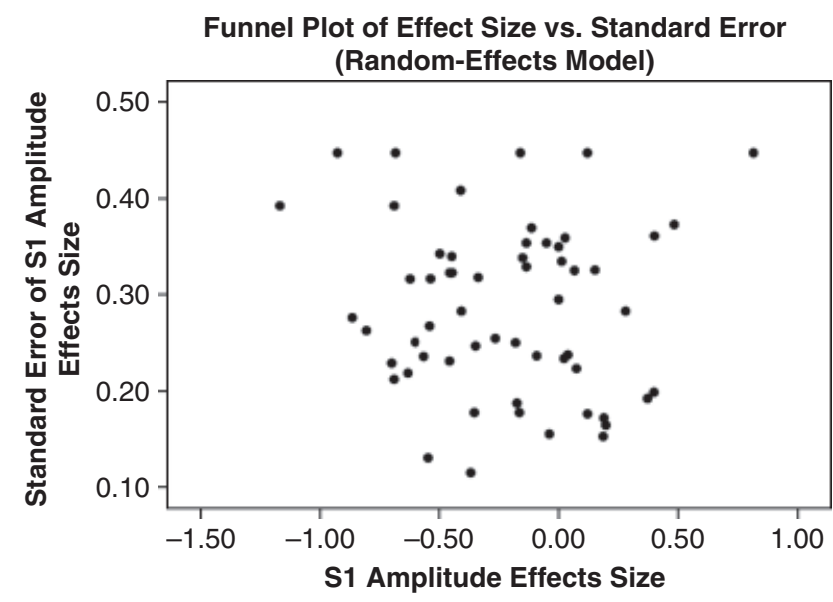

Figure 2. Funnel plot to examine publication bias in the $\mathrm{S} 1$ amplitude.

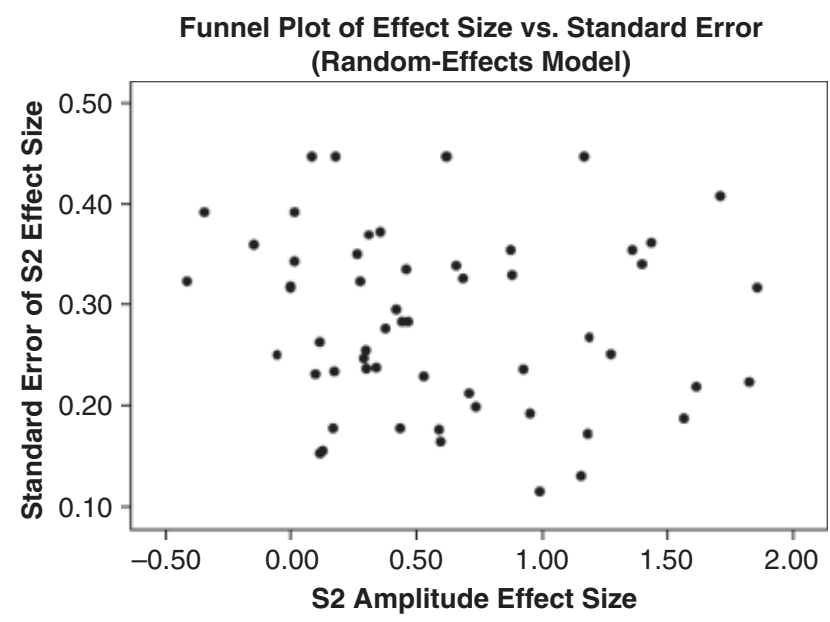

Figure 3. Funnel plot to examine publication bias in the $\mathrm{S} 2$ amplitude.
Funnel Plot of Effect Size vs. Standard Error (Random-Effects Model)

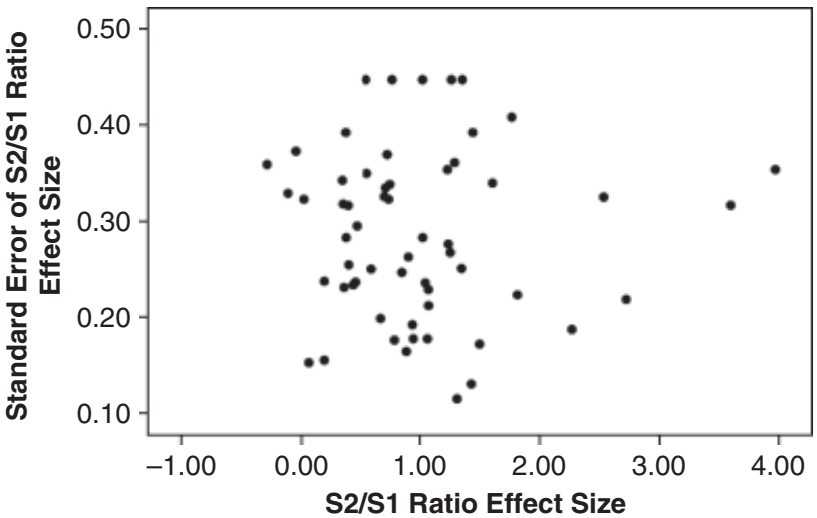

Figure 4. Funnel plot to examine publication bias in the $\mathrm{S} 2 / \mathrm{S} 1$ ratio.

The second implication is that the P50 S2/S1 ratio is an operational reflection of the brain's ability to inhibit redundant incoming sensory input, a deficiency of which remains a potential endophenotype for schizophrenia patients. In agreement with both de Wilde et al. (2007a) and Patterson et al. (2008), several concerns need to be addressed. Patterson et al. (2008) indicated that, in order to be an endophenotype, the P50 S2/S1 ratio needs to be a "reliable maker that is state-independent and enduring across different subject characteristics such as diagnostic subtype and symptom status" (p. 243) and questioned the consistency and specificity of this particular P50 measure. In addition, Gould and Gottesman (2006) list five criteria for an endophenotype. Large multicenter studies are necessary to establish the validity of putative endophenotypes or biomarkers (Olincy et al., 2010).

\section{Limitations and Future Direction}

This present meta-analysis has two major limitations. The first limitation stems from the P50 S2/S1 ratio itself. The P50 S2/S1 ratio has an inherent bias because it is a mathematical index that the $\mathrm{S} 2$ amplitude is divided by the $\mathrm{S} 1$ amplitude. As Atchley and

Table 3. Potential Moderators on Estimates of Effect Sizes of S1, S2, and S2/S1 Ratio

\begin{tabular}{|c|c|c|c|c|c|}
\hline & & \multicolumn{2}{|c|}{ Research group } & \multicolumn{2}{|c|}{ Blinding } \\
\hline & & Colorado group $(N=13)$ & Non-Colorado group $(N=45)$ & Used $(N=17)$ & Not used $(N=41)$ \\
\hline \multirow[t]{6}{*}{ S1 amplitude } & ES & -0.39 & -0.15 & 0.02 & -0.32 \\
\hline & $95 \% \mathrm{CI}$ & $-0.56--0.22$ & $-0.26--0.05$ & $-0.10-0.14$ & $-0.44-0.21$ \\
\hline & SeES & 0.087 & 0.053 & 0.063 & 0.057 \\
\hline & Q & 20.29 & 81.14 & 20.66 & 73.29 \\
\hline & & $p=.062$ & $p=.0006$ & $p=.19$ & $p=.001$ \\
\hline & $\mathrm{I}^{2}$ & $40.86 \%$ & $45.77 \%$ & $22.54 \%$ & $45.43 \%$ \\
\hline \multirow[t]{6}{*}{ S2 amplitude } & ES & 1.39 & 0.47 & 0.58 & 0.71 \\
\hline & $95 \% \mathrm{CI}$ & $0.95-1.83$ & $0.33-0.61$ & $0.36-0.81$ & $0.48-0.94$ \\
\hline & SeES & 0.225 & 0.070 & 0.116 & 0.117 \\
\hline & Q & 147.98 & 141.75 & 69.05 & 328.63 \\
\hline & & $p<.0001$ & $p<.0001$ & $p<.0001$ & $p<.0001$ \\
\hline & $\mathrm{I}^{2}$ & $91.89 \%$ & $68.96 \%$ & $76.83 \%$ & $87.83 \%$ \\
\hline \multirow[t]{6}{*}{$\mathrm{S} 2 / \mathrm{S} 1$ ratio } & ES & 1.93 & 0.72 & 0.79 & 1.08 \\
\hline & $95 \% \mathrm{CI}$ & $1.48-2.37$ & $0.58-0.86$ & $0.57-1.02$ & $0.82-1.33$ \\
\hline & SeES & 0.228 & 0.071 & 0.117 & 0.130 \\
\hline & Q & 151.38 & 146.63 & 70.63 & 406.32 \\
\hline & & $p<.0001$ & $p<.0001$ & $p<.0001$ & $p<.0001$ \\
\hline & $\mathrm{I}^{2}$ & $92.07 \%$ & $69.99 \%$ & $77.35 \%$ & $90.16 \%$ \\
\hline
\end{tabular}

Note: $\mathrm{ES}=$ effect size, $95 \% \mathrm{CI}=95 \%$ confidence interval for effect size, $\mathrm{SeES}=$ standard error of effect size. 
his colleagues indicated, when a composite score (i.e., ratio score) are used from continuous variables, a pronounced spurious correlation occurs between the ratio score and its numerator and denominator (Atchley, Gaskins, \& Anderson, 1976). In addition, Atchley et al. (1976) noticed that the size of the denominator coefficient of variation contributes to the strength of the spurious correlation. Due to this statistical nature, it is not a surprise that the previous meta-analysis (i.e., Patterson et al., 2008) examined the S1 amplitude and other investigators seek other approaches, such as the difference between S1 and S2 amplitude, to better index sensory gating. Nonetheless, we suggest that it is important to not ignore the relative contribution of the S2 amplitude because the S2 amplitude is indispensable for the ratio and difference scores.

The other major limitation is that this meta-analysis only included 35 studies (58 comparisons). Due to a lack of report- ing of either the $\mathrm{S} 1$ amplitude, S2 amplitude, and/or the P50 S2/ $\mathrm{S} 1$ ratio, many studies were not included in the present study, and they may systematically differ from those studies included. The analysis did not examine if the sensory gating deficit is specific to schizophrenia patients as the P50 gating deficit has also been reported in individuals with post-traumatic stress disorder (e.g., Ghisolfi et al., 2004), panic disorder (e.g., Ghisolfi et al., 2006), bipolar disorder (e.g., Franks, Adler, Waldo, Alpert, \& Freedman, 1983; Sánchez-Morla et al., 2008) and Alzheimer's disease (Jessen et al., 2001). The sizes of these bodies of literature are much smaller than that for schizophrenia. Therefore, it would be important to conduct other metaanalyses that compare the magnitude of differences in the S1 amplitude, S2 amplitude, and P50 S2/S1 ratio between schizophrenia patients and those psychiatric disorders when enough data has accumulated.

\section{REFERENCES}

Adler, L. E., Olincy, A., Cawthra, E. M., McRae, K. A., Harris, J. G., Nagamoto, H. T., et al. (2004). Varied effects of atypical neuroleptics on P50 auditory gating in schizophrenia patients. American Journal of Psychiatry, 161, 1822-1828.

Adler, L. E., Pachtman, E., Franks, R. D., Pecevich, M., Waldo, M. C., \& Freedman, R. (1982). Neurophysiological evidence for a defect in neuronal mechanisms involved in sensory gating in schizophrenia. Biological Psychiatry, 17, 639-654

Arnfred, S. M., Chen, A. C., Glenth $\varnothing j$, B. Y., \& Hemmingsen, R. P. (2003). Normal P50 gating in unmedicated schizophrenia outpatients. American Journal of Psychiatry, 160, 2236-2238.

Atchley, W. R., Gaskins, C. T., \& Anderson, D. (1976). Statistical properties of ratios. I. Empirical results. Systematic Zoology, 25, 137-148.

Becker, J., Gomes, I., Ghisolfi, E. S., Schuch, A., Ramos, F. L. P., Ehlers, J. A., et al. (2004). Clozapine, but not typical antipsychotics, correct P50 suppression deficit in patients with schizophrenia. Clinical Neurophysiology, 115, 396-401.

Blumenfeld, L. D., \& Clementz, B. A. (2001). Response to the first stimulus determines reduced auditory evoked response suppression in schizophrenia: Single trials analysis using MEG. Clinical Neurophysiology, 112, 1650-1659.

Boutros, N. N. (2008). Lack of blinding in gating studies. Schizophrenia Research, 103, 336-336.

Boutros, N. N., \& Belger, A. (1999). Midlatency evoked potentials attenuation and augmentation reflect different aspects of sensory gating. Biological Psychiatry, 45, 917-922.

Boutros, N. N., Brockhaus-Dumke, A., Gjini, K., Vedeniapin, A., Elfakhani, M., Burroughs, S., \& Keshavan, M. (2009). Sensory-gating deficit of the N100 mid-latency auditory evoked potential in medicated schizophrenia patients. Schizophrenia Research, 113, 339-346.

Boutros, N. N., Korzyukov, O., Jansen, B., Feingold, A., \& Bell, M. (2004). Sensory gating deficits during the mid-latency phase of information processing in medicated schizophrenia patients. Psychiatry Research, 126, 203-215.

Boutros, N. N., Zouridakis, G., \& Overall, J. (1991). Replication and extension of P50 findings in schizophrenia. Clinical Electroencephalography, 22, 40-45.

Bramon, E., Rabe-Hesketh, S., Sham, P., Murray, R. M., \& Frangou, S. (2004). Meta-analysis of the P300 and P50 waveforms in schizophrenia. Schizophrenia Research, 70, 315-329.

Brenner, C. A., Kieffaber, P. D., Clementz, B. A., Johannesen, J. K., Shekhar, A., O'Donnell, B. F., \& Hetrick, W. P. (2009). Event-related potential abnormalities in schizophrenia: A failure to "gate in" salient information? Schizophrenia Research, 113, 332-338.

Brockhaus-Dumke, A., Mueller, R., Faigle, U., \& Klosterkoetter, J. (2008a). Sensory gating revisited: Relation between brain oscillations and auditory evoked potentials in schizophrenia. Schizophrenia Research, 99, 238-249.
Brockhaus-Dumke, A., Schultze-Lutter, F., Mueller, R., Tendolkar, I., Bechdolf, A., Pukrop, R., et al. (2008b). Sensory gating in schizophrenia: P50 and N100 gating in antipsychotic-free subjects at risk, first-episode, and chronic patients. Biological Psychiatry, 64, 376-384.

Clementz, B. A., \& Blumenfeld, L. D. (2001). Multichannel electroencephalographic assessment of auditory evoked response suppression in schizophrenia. Experimental Brain Research, 139, 377-390.

Clementz, B. A., Geyer, M. A., \& Braff, D. L. (1997). P50 suppression among schizophrenia and normal comparison subjects: A methodological analysis. Biological Psychiatry, 41, 1035-1044.

Clementz, B. A., Geyer, M. A., \& Braff, D. L. (1998a). Multiple site evaluation of P50 suppression among schizophrenia and normal comparison subjects. Schizophrenia Research, 30, 71-80.

Clementz, B. A., Geyer, M. A., \& Braff, D. L. (1998b). Poor P50 suppression among schizophrenia patients and their first-degree biological relatives. American Journal of Psychiatry, 155, 1691-1694.

Cohen, J. (1988). Statistical power analysis for the behavioral sciences (2nd Ed). New York: Routledge Academic.

DerSimonian, R., \& Laird, L. (1986). Meta-analysis in clinical trials. Controlled Clinical Trials, 7, 177-188.

Devrim-Üçok, M., Keskin-Ergen, H. Y., \& Uçok, A. (2008). P50 gating at acute and post-acute phases of first-episode schizophrenia. Progress in Neuro-Psychopharmacology \& Biological Psychiatry, 32, 1952-1956.

de Wilde, O. M., Bour, L. J., Dingemans, P. M., Koelman, J. H. T. M., \& Linszen, D. H. (2007a). A meta-analysis of P50 studies in patients with schizophrenia and relatives: Differences in methodology between research groups. Schizophrenia Research, 97, 137-151.

de Wilde, O. M., Bour, L. J., Dingemans, P. M., Koelman, J. H. T. M., \& Linszen, D. H. (2007b). Failure to find P50 suppression deficits in young first-episode patients with schizophrenia and clinically unaffected siblings. Schizophrenia Bulletin, 33, 1319-1323.

Flach, K. A., Adler, L. E., Gerhardt, G. A., Miller, C., Bickford, P., \& MacGregor, R. J. (1996). Sensory gating in a computer model of the CA3 neural network of the hippocampus. Biological Psychiatry, 40, $1230-1245$.

Franks, R. D., Adler, L. E., Waldo, M. C., Alpert, J., \& Freedman, R. (1983). Neuropsychological studies of sensory gating in mania: Comparison with schizophrenia. Biological Psychiatry, 18, 989-1005.

Freedman, R., Adler, L. E., Gerhardt, G. A., Waldo, M., Baker, N., Rose, G. M., et al. (1987). Neurobiological studies of sensory gating in schizophrenia. Schizophrenia Bulletin, 13, 669-678.

Freedman, R., Waldo, M., Bickford-Wimer, P., \& Nagamoto, H. (1991). Elementary neuronal dysfunctions in schizophrenia. Schizophrenia Research, 4, 233-243.

Fresán, A., Apiquian, R., García-Anaya, M., de la Fuente-Sandoval, C., Nicolini, H., \& Graff-Guerrero, A. (2007). The P50 auditory evoked potential in violent and non-violent patients with schizophrenia. Schizophrenia Research, 97, 128-136. 
Fuerst, D. R., Gallinat, J., \& Boutros, N. N. (2007). Range of sensory gating values and test-retest reliability in normal subjects. Psychophysiology, 44, 620-626.

Ghisolfi, E. S., Heldt, E., Zanardo, A. P., Strimitzer, I. M. Jr., Prokopiuk, A. S., Becker, J., et al. (2006). P50 sensory gating in panic disorder. Journal of Psychiatric Research, 40, 535-540.

Ghisolfi, E. S., Margis, R., Becker, J., Zanardo, A. P., Strimitzer, I. M., \& Lara, D. R. (2004). Impaired P50 sensory gating in post-traumatic stress disorder secondary to urban violence. International Journal of Psychophysiology, 51, 209-214.

Gould, T. D., \& Gottesman, I. I. (2006). Psychiatric endophenotypes and the development of valid animal models. Gene, Brain and Behavior, 5 , 113-119.

Guterman, Y., \& Josiassen, R. C. (1994). Sensory gating deviance in schizophrenia in the context of task related effects. International Journal of Psychophysiology, 18, 1-12.

Hong, X., Chan, R. C. K., Zhuang, X., Jiang, T., Wan, X., Wang, J., et al. (2009). Neuroleptic effects on P50 sensory gating in patients with first-episode never-medicated schizophrenia. Schizophrenia Research, 108, 151-157.

Hong, L. E., Summerfelt, A., McMahon, R. P., Thaker, G. K., \& Buchanan, R. W. (2004). Gamma/beta oscillation and sensory gating deficit in schizophrenia. NeuroReport, 15, 155-159.

Hong, L. E., Summerfelt, A., Mitchell, B. D., McMahon, R. P., Wonodi, I., Buchanan, R. W., \& Thaker, G. K. (2008). Sensory gating endophenotype based on its neural oscillatory pattern and heritability estimate. Archives of General Psychiatry, 65, 1008-1016.

Hubel, D. H., \& Wiesel, T. N. (1959). Receptive fields of single neurones in the cat's striate cortex. Journal of Physiology, 148, 574-591.

Jansen, B. H., Hegde, A., \& Boutros, N. N. (2004). Contribution of different EEG frequencies to auditory evoked potential abnormalities in schizophrenia. Clinical Neurophysiology, 115, 523-533.

Jessen, F., Kucharski, C., Fries, T., Papassotiropoulos, A., Hoenig, K., Maier, W., \& Heun, R. (2001). Sensory gating deficit expressed by a disturbed suppression of the P50 event-related potential in patients with Alzheimer's disease. American Journal of Psychiatry, 158, 1319-1321

Jin, Y., Potkin, S. G., Patterson, J. V., Sandman, C. A., Hetrick, W. P., \& Bunney, W. E. (1997). Effects of P50 temporal variability on sensory gating in schizophrenia. Psychiatry Research, 70, 71-81.

Johannesen, J. K., Kieffaber, P. D., O'Donnell, B. F., Shekhar, A., Evans, J. D., \& Hetrick, W. P. (2005). Contributions of subtype and spectral frequency analyses to the study of P50 ERP amplitude and suppression in schizophrenia. Schizophrenia Research, 78, 269-284.

Kathmann, N., \& Engel, R. R. (1990). Sensory gating in normals and schizophrenics: A failure to find strong P50 suppression in normals. Biological Psychiatry, 27, 1216-1226.

Kisley, M. A., Olincy, A., Robbins, E., Polk, S. D., Adler, L. E., Waldo, M. C., \& Freedman, R. (2003). Sensory gating impairment associated with schizophrenia persists into REM sleep. Psychophysiology, 40, 29-38.

Louchart-de la Chapelle, S., Levillain, D., Menard, J. F., van der Elst, A., Allio, G., Haouzir, S., et al. (2005). P50 inhibitory gating deficit is correlated with the negative symptomatology of schizophrenia. Psychiatry Research, 136, 27-34.

Martin, L. F., Leonard, S., Hall, M. H., Tregellas, J. R., Freedman, R., \& Olincy, A. (2007). Sensory gating and alpha-7 nicotinic receptor gene allelic variants in schizoaffective disorder, bipolar type. American Journal of Medical Genetics Part B (Neuropsychiatric Genetics), $144 B, 611-614$.

Moxon, K. A., Gerhardt, G. A., Gulinello, M., \& Adler, L. E. (2003). Inhibitory control of sensory gating in a computer model of the CA3 region of the hippocampus. Biological Cybernetics, 88, 247-264.
Myles-Worsley, M. (2002). P50 sensory gating in multiplex schizophrenia families from a Pacific island isolate. American Journal of Psychiatry, 159, 2007-2012.

Olincy, A., Braff, D. L., Adler, L. E., Cadenhead, K. S., Calkins, M. E., Dobie, D. J., et al. (2010). Inhibition of the P50 cerebral evoked response to repeated auditory stimuli: Results from the Consortium on Genetics of Schizophrenia. Schizophrenia Research, 119, 175-182.

Olincy, A., Ross, R. G., Harris, J. G., Young, D. A., McAndrews, M. A., Cawthra, E., et al. (2000). The P50 auditory event-evoked potential in adult attention-deficit disorder: Comparison with schizophrenia. Biological Psychiatry, 47, 969-977.

Orwin, R. G. (1983). A fail-safe $N$ for effect size in meta-analysis. Journal of Educational and Behavioral Statistics, 8, 157-159.

Patterson, J. V., Hetrick, W. P., Boutros, N. N., Jin, Y., Sandman, C., Stern, H., et al. (2008). P50 sensory gating ratios in schizophrenics and controls: A review and data analysis. Psychiatry Research, 158, 226-247.

Patterson, J. V., Jin, Y., Gierczak, M., Hetrick, W. P., Potkin, S., Bunney, W. E. Jr., \& Sandman, C. A. (2000). Effects of temporal variability on P50 and the gating ratio in schizophrenia: A frequency domain adaptive filter single-trial analysis. Archives of General Psychiatry, 57, 57-64.

Rentzsch, J., Jockers-Scherübl, M. C., Boutros, N. N., \& Gallinat, J. (2008). Test-retest reliability of P50, N100 and P200 auditory sensory gating in healthy subjects. International Journal of Psychophysiology, 67, 81-90.

Rentzsch, J., Penzhorn, A., Kernbichler, K., Plöckl, D., Gómez-Carrillo de Castro, A., Gallinat, J., \& Jockers-Scherübl, M. C. (2007). Differential impact of heavy cannabis use on sensory gating in schizophrenic patients and otherwise healthy controls. Experimental Neurology, 205, 241-249.

Sánchez-Morla, E. M., García-Jiménez, M. A., Barabash, A., MartínezVizcaíno, V., Mena, J., Cabranes-Díaz, J. A., et al. (2008). P50 sensory gating deficit is a common marker of vulnerability to bipolar disorder and schizophrenia. Acta Psychiatrica Scandinavica, 117, 313-318.

Sánchez-Morla, E. M., Santos, J. L., Aparicio, A., García-Jiménez, M. A., Villanueva, C., Martínez-Vizcaíno, V., \& Arango, C. (2009). Antipsychotic effects on auditory sensory gating in schizophrenia patients. European Neuropsychopharmacology, 19, 905-909.

Smith, D. A., Boutros, N. N., \& Schwarzkopf, S. B. (1994). Reliability of P50 auditory event-related potential indices of sensory gating. Psychophysiology, 31, 495-502.

Turetsky, B. I., Bilker, W. B., Siegel, S. J., Kohler, C. G., \& Gur, R. E. (2009). Profile of auditory information-processing deficits in schizophrenia. Psychiatry Research, 165, 27-37.

Venables, P. H. (1964). Input dysfunction in schizophrenia. In B. A. Mahler (Ed.), Progress in Experimental Personality Research (pp. 1-47). Orlando, FL: Academic Press.

Yee, C. M., Nuechterlein, K. H., Morris, S. E., \& White, P. M. (1998). P50 suppression in recent-onset schizophrenia: Clinical correlates and risperidone effects. Journal of Abnormal Psychology, 107, 691-698.

Zakzanis, K. K. (2001). Statistics to tell the truth, the whole truth, and nothing but the truth: Formulae, illustrative numerical examples, and heuristic interpretation of effect size analyses for neuropsychological researchers. Archives of Clinical Neuropsychology, 16, 653-667.

Zouridakis, G., \& Boutros, N. N. (1992). Stimulus parameter effects on the P50 evoked response (Brief Report). Biological Psychiatry, 32, 839-841.

(RECEIVED March 29, 2010; ACCEPTED November 13, 2010)

[Correction added after online publication January 7, 2011: In the title, "meta-alysis" should have read "meta-analysis." The corrected version appears here.] 